Nat. Hazards Earth Syst. Sci., 19, 629-653, 2019

https://doi.org/10.5194/nhess-19-629-2019

(C) Author(s) 2019. This work is distributed under the Creative Commons Attribution 4.0 License.

\title{
Application of the Levenburg-Marquardt back propagation neural network approach for landslide risk assessments
}

\author{
Junnan Xiong ${ }^{1,3}$, Ming Sun ${ }^{2}$, Hao Zhang ${ }^{1}$, Weiming Cheng ${ }^{3}$, Yinghui Yang ${ }^{1}$, Mingyuan $\operatorname{Sun}^{1}$, Yifan Cao ${ }^{1}$, and \\ Jiyan Wang ${ }^{1}$ \\ ${ }^{1}$ School of Civil Engineering and Architecture, Southwest Petroleum University, Chengdu, 610500, P.R. China \\ ${ }^{2}$ The First Surveying and Mapping Engineering Institute of Sichuan Province, Chengdu, 610100, P.R. China \\ ${ }^{3}$ State Key Laboratory of Resources and Environmental Information System, Institute of Geographic Science \\ and Natural Resources Research, Chinese Academy of Sciences, Beijing, 100101, P.R. China
}

Correspondence: Junnan Xiong (neu_xjn@163.com) and Hao Zhang (zhanghao412658@163.com)

Received: 28 November 2018 - Discussion started: 6 December 2018

Revised: 25 February 2019 - Accepted: 27 February 2019 - Published: 25 March 2019

\begin{abstract}
Landslide disasters are one of the main risks involved with the operation of long-distance oil and gas pipelines. Because previously established disaster risk models are too subjective, this paper presents a quantitative model for regional risk assessment through an analysis of the patterns of historical landslide disasters along oil and gas pipelines. Using the Guangyuan section of the LanzhouChengdu-Chongqing (LCC) long-distance multiproduct oil pipeline $(82 \mathrm{~km})$ in China as a case study, we successively carried out two independent assessments: a susceptibility assessment and a vulnerability assessment. We used an entropy weight method to establish a system for the vulnerability assessment, whereas a Levenberg-Marquardt back propagation (LM-BP) neural network model was used to conduct the susceptibility assessment. The risk assessment was carried out on the basis of two assessments. The first, the system of the vulnerability assessment, considered the pipeline position and the angle between the pipe and the landslide (pipeline laying environmental factors). We also used an interpolation theory to generate the standard sample matrix of the LM-BP neural network. Accordingly, a landslide susceptibility risk zoning map was obtained based on susceptibility and vulnerability assessment. The results show that about $70 \%$ of the slopes were in high-susceptibility areas with a comparatively high landslide possibility and that the southern section of the oil pipeline in the study area was in danger. These results can be used as a guide for preventing and reducing regional hazards, establishing safe routes for both existing and new
\end{abstract}

pipelines, and safely operating pipelines in the Guangyuan area and other segments of the LCC oil pipeline.

\section{Introduction}

By the year 2020, the total length of long-distance oil and gas pipelines is expected to exceed $160000 \mathrm{~km}$ in China. This represents a major upsurge in the length of multinational long-distance oil and gas pipelines (Huo et al., 2016). The rapid development of pipelines is associated with significant geological hazards, especially landslides, which increasingly threaten the safe operation of pipelines (Wang et al., 2012; Yun and Kang, 2014; Zheng et al., 2012). Landslide disasters cause great harm to infrastructure and human life. Moreover, the wide impact area of landslides restricts the economic development of landslide-prone areas (Ding et al., 2016; Hong et al., 2015). A devastating landslide can lead to casualties, property loss, environmental damage, and long-term service disruptions caused by massive oil and gas leakages (G. Li et al., 2016; Zheng et al., 2012). Generally, pipeline failure or destruction caused by landslides is much more deleterious than the landslides themselves, which makes it important to research the risk assessment of geological landslide hazards in pipeline areas (Inaudi and Glisic, 2006; Mansour et al., 2011).

Natural disaster risk is comprised of a combination of natural and social attributes (Atta-Ur-Rahman and Shaw, 2015). The United Nations Department of Humanitarian Af- 
fairs defines natural disaster risk as a product of susceptibility and vulnerability (Rafiq and Blaschke, 2012; Sari et al., 2017). In recent years, progress in geographic information systems (GIS) and remote sensing (RS) technologies have greatly enhanced our ability to evaluate the potential risks that landslides pose to pipelines (Akgun et al., 2012; Li and Gao, 2015; Sari et al., 2017). The disaster risk assessment model has been widely recognized and applied by experts and scholars all over the world. Landslide risk assessment can take the form of a qualitative (Wu et al., 1996), quantitative (Ho et al., 2000) or semiquantitative assessment (Liu et al., 2015) according to actual demand. Quantitative methods and models that have been proposed for the assessment can be divided into methods of statistical analysis (Sari et al., 2017), mathematical models (Akgun et al., 2012) and machine learning ( $\mathrm{He}$ and $\mathrm{Fu}, 2009$ ). However, most of these methods are subjective, such as expert evaluations, analytical hierarchy processes, logistic regressions and fuzzy integration methods, which could affect the accuracy and reasonableness of the evaluation (Fall et al., 2006; Sarkar and Gupta, 2005). This shortcoming can be overcome through the artificial neural network, especially the mature back propagation (BP) neural network that is widely used in function approximation and pattern recognition ( $\mathrm{Ke}$ and $\mathrm{Li}, 2014 \mathrm{a}$; Li et al., 2013; Su and Deng, 2003). The evaluation indicator system generally includes disaster characteristics, disaster prevention and pipeline attributes (Li, 2008, 2010). The fault tree analysis, fuzzy comprehensive evaluation and the grey theory are used to evaluate the failure probability of the system through indicator weight and scoring (Shi, 2011; Ye et al., 2013). In previous studies, pipeline vulnerability evaluation indicators only considered the pipeline itself, and the relationship between the pipeline and environment was rarely examined (Feng et al., 2014; Li, 2008; Liu et al., 2015). In this paper, the interaction between landslide hazards and the pipeline itself was considered, which improved the quantitative degree of the evaluation.

Based on the theory of the Levenberg-Marquardt back propagation (LM-BP) neural network, a standard sample matrix was developed using interpolation theory, after an analysis of the distribution characteristics of landslides that occurred in the study area was performed and a regional landslide susceptibility assessment was completed. Considering the interaction between landslide disasters and the pipeline itself, a pipeline vulnerability evaluation in the landslide area was realized using the entropy weight method. This paper establishes a risk assessment model and methods for assessing landslide geological susceptibility of oil pipelines by comprehensively utilizing GIS and RS technology, which together improves the quantitative degree of the assessment.

\section{Study area}

The study area was Guangyuan City in Sichuan province, which was further narrowed to the area from $105^{\circ} 15^{\prime}$ to $106^{\circ} 04^{\prime} \mathrm{E}$ and $32^{\circ} 03^{\prime}$ to $32^{\circ} 45^{\prime} \mathrm{N}$, straddling 19 townships in five counties from south to north (Fig. 1). The LanzhouChengdu-Chongqing (LCC) multiproduct oil pipeline is China's first long-distance pipeline. It begins in Lanzhou City and runs through Shanxi and Sichuan provinces (Hao and Liu, 2008). Our study area covered sloped areas of this range, with $5 \mathrm{~km}$ on both sides of the Guangyuan section $(82 \mathrm{~km})$ of the oil pipeline. The pipeline within the K558-K642 pipes may be affected by the slope areas. The Guangyuan section, located in northern Sichuan, is a transitional zone from the basin area to the mountain area. It features terrain of moderate and low mountains, crisscrossed networks of ravines and a strong fluvial incision. Altitudes in this area range from 328 to $1505 \mathrm{~m}$. The study area has a subtropical monsoon climate with four distinctive seasons and annual precipitation measuring about 900 to $1000 \mathrm{~mm}$. Moreover, two large unstable faults (the central fault of the Longmen Mountains and Longmen Mountains' Piedmont fault zone) make the area geologically unstable and prone to frequent geological hazards (Li et al., 2012). Guangyuan, through which the pipeline passes, has a high incidence of landslides, which have happened 300 times in the Lizhou and Chaotian districts (Zhang et al., 2011). In this area, landslide geological hazards seriously threaten the safe operation of the LCC oil pipeline.

\section{Data sources}

Landslide susceptibility assessment, pipeline vulnerability assessment and geological hazard risk assessment of the landslide pipeline were made successively. Digital elevation model (DEM) data with $30 \mathrm{~m}$ accuracy were sourced from the Geospatial Data Cloud (http://www.gscloud.cn/, last access: January 2017. Precipitation data were downloaded from the dataset of annual surface observation values in China between the years 1981 and 2010, as published by the China Meteorological Administration (http://data.cma.cn/, last access: January 2017). These data were collected from 18 meteorological observatories near and within the study area and interpolated using the kriging method (at a resolution of $30 \mathrm{~m} \times 30 \mathrm{~m}$ ). Geological maps and landslide data (historical landslides) in the study area were obtained from Sichuan province's geological environmental monitoring station. RS images (GF-1, multispectral $8 \mathrm{~m}$, resolution $2 \mathrm{~m}$ ) were provided by the Sichuan Remote Sensing Center.

The location of the middle line of the pipeline was detected through the direct connection method (i.e., the transmitter's output line was directly connected to the metal pipeline) using an RD8000 underground pipeline detector. Pipeline midline coordinates were measured using total network real-time 


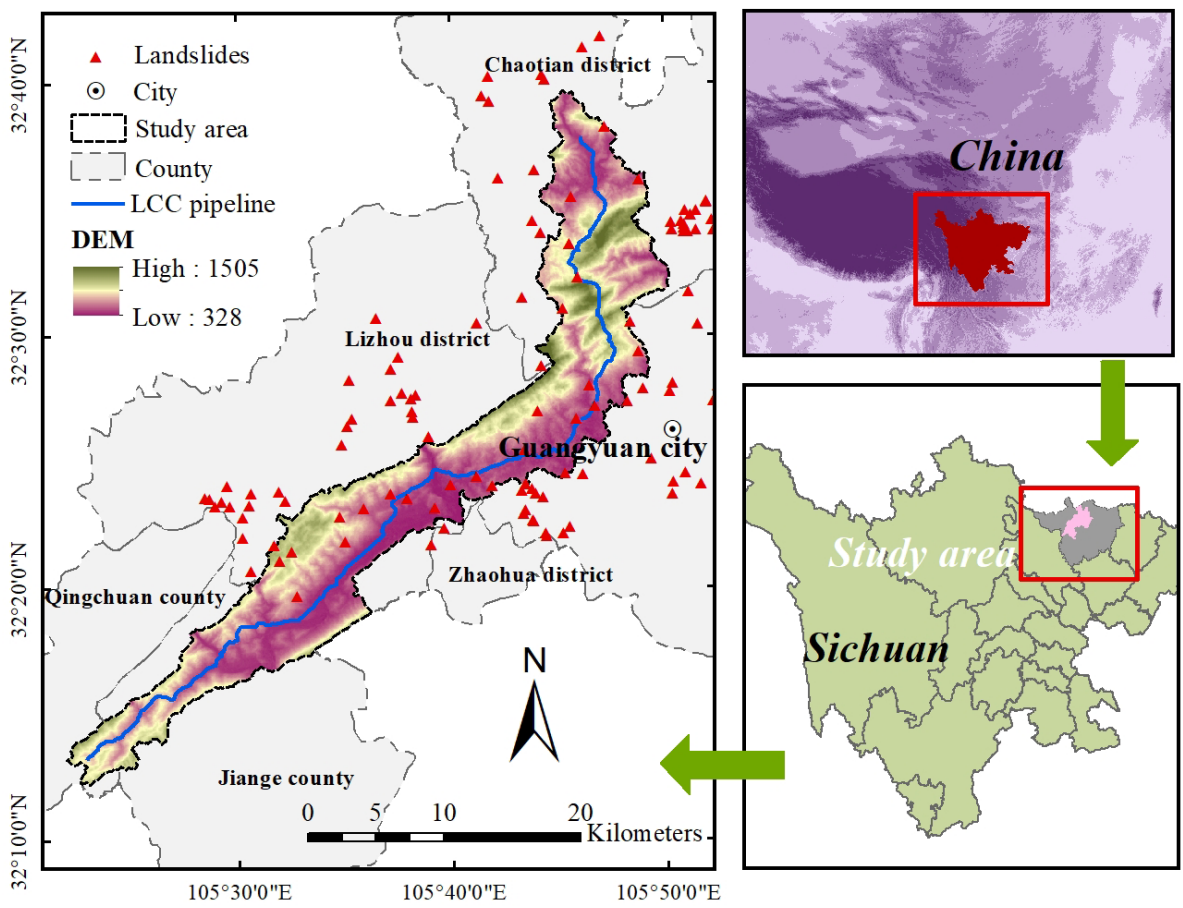

Figure 1. Landslide location map of the study area.

kinematic technology, and, simultaneously, the coordinates of the pipe ancillary facilities (including detective poles, mileage pegs and milestones) were acquired. Mileage data obtained through inner pipeline detection were derived from the China Petroleum Pipeline Company.

\section{Methods}

\subsection{Assessment unit}

Division precision and the scale of the slope unit (i.e., the basic element for a regional landslide susceptibility assessment) were in keeping with the results of the evaluation (Qiu et al., 2015). A total of 315 slope units were divided using hydrologic analysis in ArcGIS (v. 10.4) (Fig. 2a). The irrational unit (a slope unit with an inaccurate boundary) was artificially identified and modified by comparing GF-1 satellite remote sensing images. Boundary correction, fragment combination and fissure filling were used for modification.

This vulnerability study focuses on assessing the vulnerability of transport pipelines to landslides. Considering both previous research and the particulars of the research object, we used a comprehensive segmentation method based on GIS to divide the pipelines in our study. A total of 180 pipes were divided in the study area, of which the longest was about $1.7 \mathrm{~km}$, and the shortest was only about $10 \mathrm{~m}$ (Fig. 2b).

\subsection{Assessment indicators}

Based on selection principles of the indicator system and the formation mechanism of landslide geological hazards, as few indicators as possible were selected to reflect the degree of danger posed by the landslide as accurately as possible (Avalon Cullen et al., 2016; Jaiswal et al., 2010; Ray et al., 2007). The internal factors in these indicators included topography, geological structure, stratigraphic lithology and surface coverage. Similarly, the external factors included mean annual precipitation (MAP) and the coefficient of the variation of annual rainfall (CVAR). The correlations between indicators were analyzed using R (v. 3.3.1), and the results show a significant correlation between MAP and CVAR $(R=0.99)$ and between the normalized difference water index (NDWI) and normalized differential vegetation index (NDVI) $(R=0.87)$. Based on correlation and standard deviation, CVAR and NDWI were eliminated from the original evaluation system for the landslide susceptibility assessment in the pipeline area (Table 1).

Generally, the evaluation indicator of pipeline vulnerability as it relates to the relationship between a pipeline and its surrounding environment is rarely considered. The evaluation indicators in this paper were refined to include pipeline parameters and the spatial relationship between a pipeline and a landslide. The pipelines in the study area were based in mountainous areas and have been running for many years. All of these pipelines consisted of high-pressure pipes that were made of steel tubes and had a diameter of $610 \mathrm{~mm}$ 


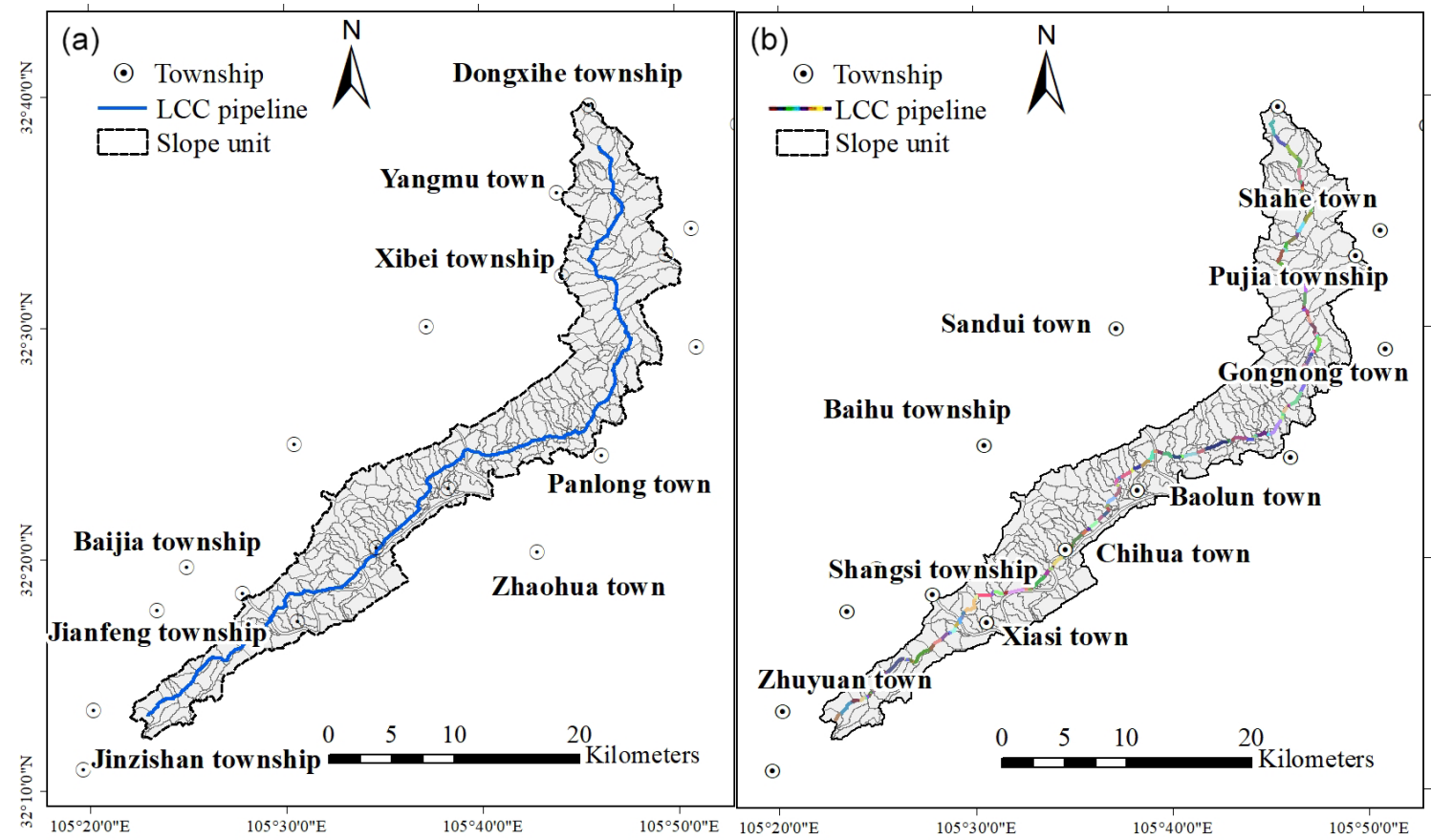

Figure 2. All slope units (a) and pipeline sections (b) in the study area.

Table 1. Indicators of landslide susceptibility assessment and pipeline vulnerability assessment.

\begin{tabular}{lll}
\hline & Factor & Indicators \\
\hline Landslide & & Elevation \\
hazard & & Slope \\
indicator & Landform & Aspect \\
& & Height difference \\
& & Topographic profile curvature (TPC) \\
\cline { 2 - 3 } & Land cover & Normalized differential vegetation index (NDVI) \\
& & Normalized difference water index (NDWI) \\
\cline { 2 - 3 } & Geology & Lithology \\
\cline { 2 - 3 } & & Distance from the fault \\
\cline { 2 - 3 } Pipeline \\
vulnerability & Precipitation & Mean annual precipitation (MAP) \\
& & Coefficient of variation of annual rainfall (CVAR) \\
& & Defect density \\
& & Depth \\
& Pipe body & Thickness \\
& & Pressure \\
& & Materials \\
& & Diameter \\
& & Media \\
\cline { 2 - 3 } & Spatial relationship between & Position \\
& pipeline and landslide & Angle \\
\hline
\end{tabular}

for conveying oil. In keeping with the theory of the entropy weight method, these indicators (e.g., pressure, materials, diameter and media) were not included in the final evaluation system used to determine pipeline vulnerability.

\subsection{LM-BP neural network model}

A neural network is a nonlinear mathematical structure which is capable of representing complex nonlinear pro- 
cesses that relate the inputs and outputs of any system (Hsu et al., 1995). With its good performance in nonlinear statistical modeling, it is very useful in exploring the hidden relationships between the inputs and the outputs $(\mathrm{Wu}$ and Wang, 2016). A BP neural network with many adjustable parameters has a powerful parallel processing mechanism, high flexibility and can incorporate uncertainty information well. The mechanism of landslide evaluation is complex with many uncertainties and incomplete information (Jie et al., 2015). The BP neural network model can calculate the intrinsic rules from the vast amount of complex and fuzzy data in the changing environment and make corresponding inferences. The information about landslides reflected by the data used in the process of susceptibility assessment is mostly qualitative rather than quantitative. Through the analysis of this fuzzy information, accurate assessment results can be obtained. Landslide susceptibility assessment is essentially a study of pattern recognition (Feng et al., 2017). The BP neural network can approximate arbitrary continuous function with arbitrary precision, so it is widely used in nonlinear modeling, pattern recognition and pattern classification (Xiong et al., 2010). Because the BP neural network model is widely used, there are many successful cases as a reference for the number of neurons in each layer, the parameters of network learning and the optimization of algorithms, which can effectively improve the reliability and accuracy of the model (Ke and Li, 2014b).

The LM algorithm, also known as the damped leastsquares method, has the advantage of local fast convergence. Its strong global searching ability contributes to the strong extrapolation ability of the trained network. The LM algorithm is a combination of the gradient descent method and Gauss-Newton method. Its iteration process is no longer along a single negative gradient direction, which greatly improves the convergence speed and generalization ability of the network (Li et al., 2016). The BP neural network model, optimized by the LM algorithm, was used to evaluate the regional landslide susceptibility in this study. MATLAB 2014 with the trainlm training function was used to implement the LM-BP neural network. The flowchart of LM-BP neural network algorithm is shown in Fig. 3.

Data from 106 landslide disasters were collected near the research area. Of these landslides, 23 were within the region of the study area. Most of the landslides located outside the study area were less than $20 \mathrm{~km}$ away from the pipeline. Due to comparable environmental conditions, these landslides could still help us identify the relationship between landslides and environment factors. In light of the frequency distribution of each evaluation indicator (Fig. 4), the landslide susceptibility grade corresponding to each interval of the indicators was divided, and then the susceptibility degree monotonicity in each interval was decided. For this study, the landslide susceptibility grade was divided into four levels: low (I), medium (II), high (III) and extremely high (IV). Based on previous research experience and field investiga-

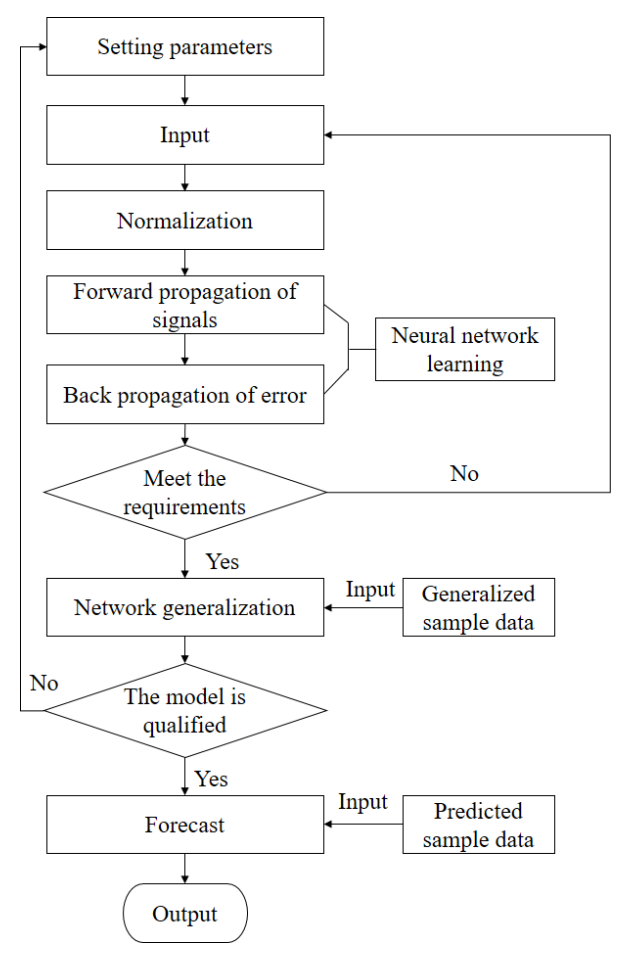

Figure 3. Flowchart of the LM-BP neural network algorithm.

tions (Appendix $\mathrm{H}$ ), the monotonous intervals of different indicators of susceptibility degrees were judged (Appendix A). For instance, there were hardly any landslides, only collapses that occurred in slopes above $60^{\circ}$. Besides, the susceptibility degree in the area was monotone decreasing in the slope interval of 60 to $90^{\circ}$. Because of the very small sliding force in slopes at 0 to $15^{\circ}$, landslides were rare to occur here, even under other extreme conditions (Zhang et al., 2015). On the basis of the classification criteria of the evaluation indicators used to predict landslide susceptibility degree and the functional relationship between the evaluation indicators and landslide probabilities, standard samples (training samples and test samples) were built using a specific mathematical method. When establishing the empty matrix, the sample size of each landslide susceptibility level was set to 200, and the training sample size was 800 . According to the order of susceptibility from low to high (Appendix A), the input was constructed by interpolating for each interval. The interval of the susceptibility degree is $[0,1]$, and the output is obtained by interpolating 800 values equidistantly between the interval of $[0,1]$ (Appendix B). Using interpolation theory to build samples avoided the excess human influence in the process of building a neural network model by traditional methods. The training samples and test samples were evaluated using similar construction methods but with different sample sizes. Finally, the indicator data were normalized, they were entered into the LM-BP neural network for simulation and 315 slope unit landslide susceptibility values were output. 

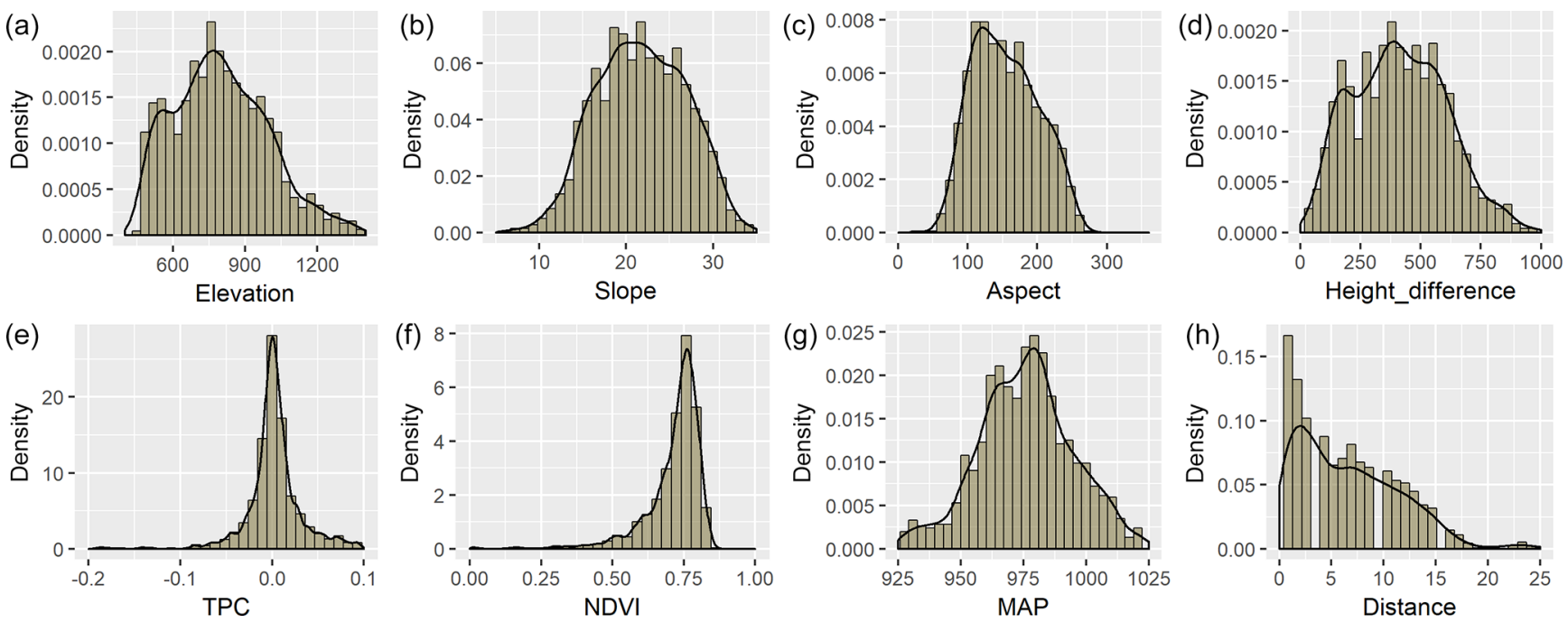

Figure 4. The frequency distribution of each indicator in the landslide location. Maps (a), (b), (c), (d), (e), (f), (g) and (h) represent the elevation, slope, aspect, height difference, TPC, NDVI, MAP and distance from the fault, respectively.

\subsection{Vulnerability assessment model for pipelines}

The vulnerability evaluation model of pipelines in the landslide area was established using the entropy weight method, which overcame the shortcomings of the traditional weight method that does not consider the different evaluation indicators and the excessive human influence on the process of evaluation (Gao et al., 2017; Pal, 2014). Entropy is a method of measuring the uncertainty of information by using probability theory (Liu and Zhang, 2011). The entropy indicates the extent of difference in an indicator: the more different the data, the greater the role in evaluation (Jia et al., 2007). The extremum difference method difference method was used to normalize each indicator value. The decision information of each index can be expressed by entropy value $e_{i}$ :

$r_{i j}=\frac{x_{i j}-\min _{j}\left\{x_{i j}\right\}}{\max _{j}\left\{x_{i j}\right\}-\min _{j}\left\{x_{i j}\right\}}$,

$r_{i j}=\frac{\max _{j}\left\{x_{i j}\right\}-x_{i j}}{\max _{j}\left\{x_{i j}\right\}-\min _{j}\left\{x_{i j}\right\}}$,

$e_{i}=\frac{\sum_{j=1}^{n} p\left(x_{i j}\right) \ln p\left(x_{i j}\right)}{\ln (n)}$,

$p\left(x_{i j}\right)=\frac{r_{i j}}{\sum_{j=1}^{n} r_{i j}}$,

$w_{i}=\frac{1-e_{i}}{m-\sum_{i=1}^{m} e_{i}}$,

$H_{j}=\sum_{i=1}^{m} w_{i} r_{i j}$ where $n$ is the number of evaluation objects, and $r_{i j}$ represents the $i$ th evaluation indicator values of $j$ th pipe sections. $H_{j}$ is the evaluation value of the pipeline section's vulnerability; $w_{i}$ is the weight of the evaluation indicator.

Pipeline defect density was obtained from the pipeline internal inspection data, which consisted of both mileage data that needed to be converted into three-dimensional coordinate data and pipeline centerline coordinate data obtained through C\# programming. In addition, the main slide direction of the landslide was replaced by the slope direction that was extracted by the DEM. The coordinate azimuth of the pipe section was extracted using the linear vector data of each pipe section, and the angle between the pipeline and the slope was calculated using the mathematical method. The calculation process was solved in the Visual Basic language on ArcGIS using second development functions. Finally, the entropy weight of 5 indicators was calculated by programming in MATLAB 2014. The entropy weight calculation results for pipeline landslide vulnerability assessment are shown in Table 2.

\section{Results and comparison}

\subsection{Regional landslide susceptibility assessment}

The LM-BP neural network was trained and the network was stopped after 182 iterations. An RMSE value of $9.93 \times$ $10^{-9}$ indicated that the goal of precision had been reached. Through the simulation of the network test, none of the absolute error values of test data (20 groups) were found to be greater than 0.02 ; this result aligned with our expectation of the precision of the landslide susceptibility assessment. The landslide susceptibility grade was divided into four levels by 
Table 2. Entropy weight of evaluation indicator.

\begin{tabular}{lrrrrr}
\hline & Depth & Angle & Defect density & Thickness & Position \\
\hline Weight & 0.010007 & 0.101553 & 0.678851 & 0.154322 & 0.055266 \\
Entropy & 0.997322 & 0.97282 & 0.818308 & 0.958696 & 0.985208 \\
\hline
\end{tabular}

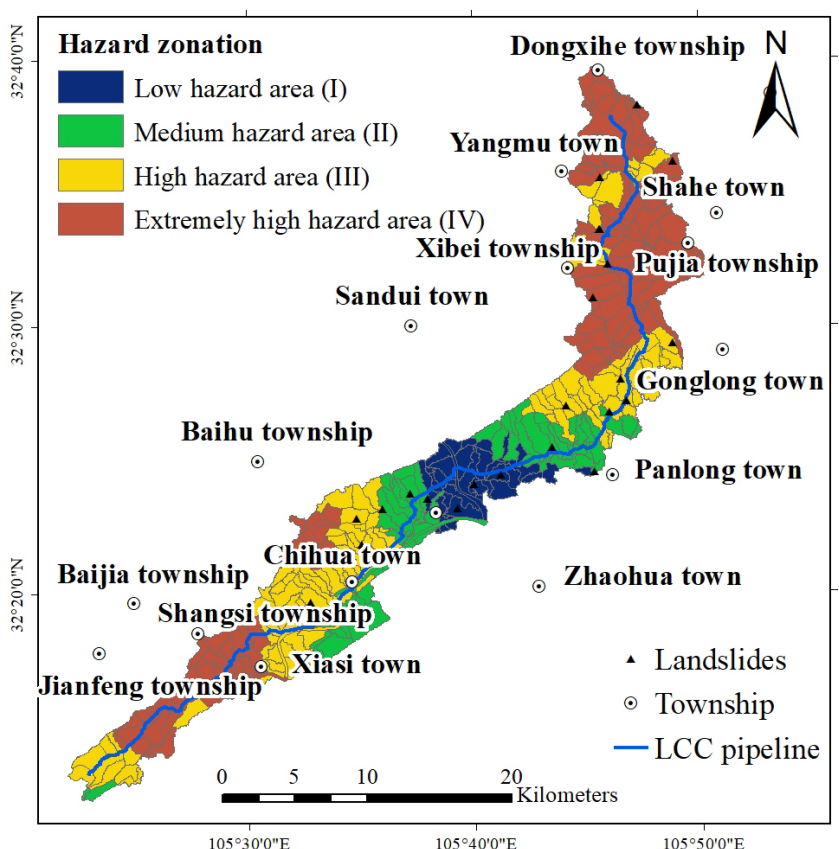

Figure 5. Landslide hazard map of study area.

using the equal interval method at intervals of 0.25 . The safe (low-susceptibility) section was located in the central part of the study area. The dangerous (high-susceptibility) section was located north and south (Fig. 5). In the study area, most of the exposed rock was dominated by shale, which belongs to the easy-slip rock group.

Average altitude ranged from 450 to $1400 \mathrm{~m}$, and the relative height difference was greater than $80 \mathrm{~m}$, with the slope between 15 and $35^{\circ}$. Based on an overlay analysis of historic landslides within the study area, and susceptibility zonation maps, we surmised that the probability of landslides in the study area was extremely high, and that $87 \%$ of the landslides occurred in the medium-, high-, and extremely high-susceptibility areas. Among these landslides, three were located in low-susceptibility areas, which accounted for $13 \%$ of the landslide disaster sites, five occurred in medium-susceptibility areas (accounting for $21.7 \%$ of disaster sites), seven occurred in high-susceptibility areas (accounting for $30.4 \%$ of sites) and eight occurred in extremely high-susceptibility areas (accounting for $34.8 \%$ of sites). The evaluation results were found to accurately reflect the trends and rules of distribution of landslides in the study area. The number and area of slopes in high-susceptibility and ex-
Table 3. Number and area of slopes of four hazard grades.

\begin{tabular}{lrrrr}
\hline $\begin{array}{l}\text { Landslide } \\
\text { susceptibility }\end{array}$ & $\begin{array}{r}\text { Number of } \\
\text { slopes }\end{array}$ & $\begin{array}{r}\text { Percen- } \\
\text { tage }(\%)\end{array}$ & $\begin{array}{r}\text { Area } \\
\left(\mathrm{km}^{2}\right)\end{array}$ & $\begin{array}{r}\text { Percen- } \\
\text { tage }(\%)\end{array}$ \\
\hline Low (I) & 33 & 10.48 & 32.63 & 8.76 \\
Medium (II) & 62 & 19.68 & 65.53 & 17.60 \\
High (III) & 112 & 35.56 & 123.55 & 33.18 \\
Extremely high (IV) & 108 & 34.29 & 150.65 & 40.46 \\
Total & 315 & 100 & 372.36 & 100 \\
\hline
\end{tabular}

Table 4. Number and distances of pipeline of four vulnerability grades.

\begin{tabular}{lrrrr}
\hline $\begin{array}{l}\text { Pipeline } \\
\text { vulnerability }\end{array}$ & $\begin{array}{r}\text { Number of } \\
\text { pipelines }\end{array}$ & $\begin{array}{r}\text { Percen- } \\
\text { tage }(\%)\end{array}$ & $\begin{array}{r}\text { Area } \\
\left(\mathrm{km}^{2}\right)\end{array}$ & $\begin{array}{r}\text { Percen- } \\
\text { tage }(\%)\end{array}$ \\
\hline Low (I) & 120 & 66.66 & 50.417 & 62.06 \\
Medium (II) & 37 & 20.56 & 20.888 & 25.72 \\
High (III) & 22 & 12.22 & 9.833 & 12.11 \\
Extremely high (IV) & 1 & 0.56 & 0.087 & 0.11 \\
Total & 180 & 100 & 81.225 & 100 \\
\hline
\end{tabular}

tremely high-susceptibility areas accounted for about $70 \%$ of the total (Table 3). The probability of landslide occurrence in the study area was generally high, which was consistent with the fact that the region was landslide-prone.

\subsection{Vulnerability assessment for oil pipeline in landslide area}

The equal interval of 0.25 was used to divide the pipeline vulnerability level into four grades to obtain the pipeline vulnerability zonation of the study area (Fig. 6). The pipeline in the northern part of the study area was given a low vulnerability grade, while the situation in the south of the region is more serious. The number, length and percentage of pipeline segments with different grade vulnerabilities are shown in Table 4 . The number and length of pipeline segments in highly vulnerable areas (III) and extremely vulnerable areas (IV) accounted for about $12 \%$ of the total.

\subsection{Risk assessment for oil pipeline in landslide area}

According to natural disaster risk expressions released by the $\mathrm{UN}$, the definition of risk may be expressed as the product of landslide susceptibility in a pipeline area and pipeline vulnerabilities in the landslide area. Scientific analysis and expression of disaster risk assessment results can simplify com- 


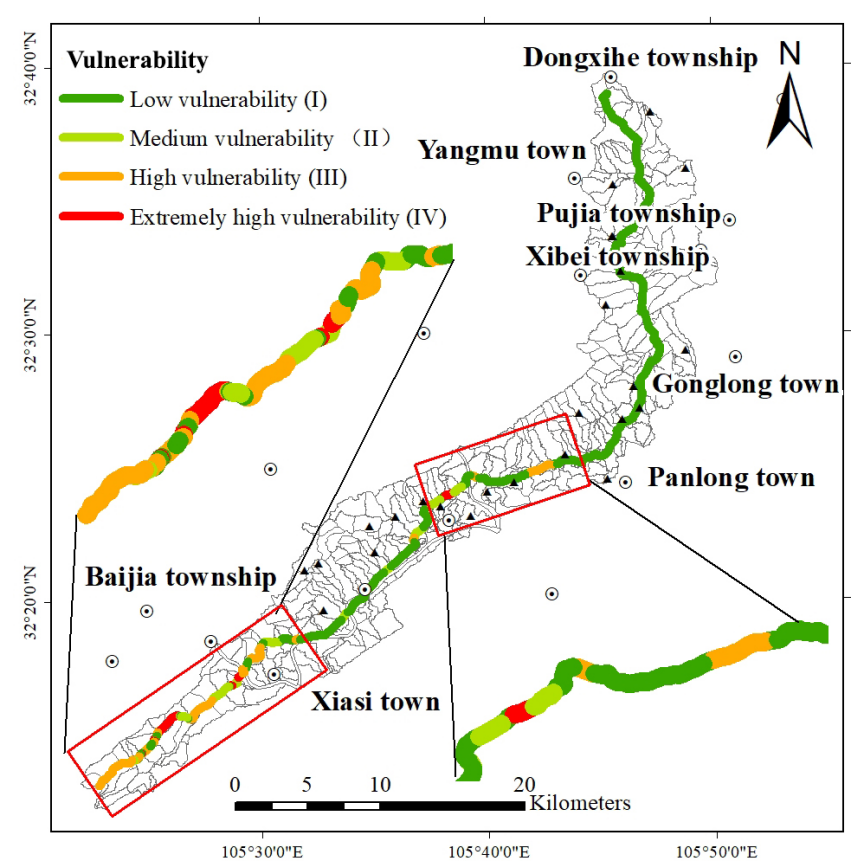

Figure 6. Pipeline vulnerability map of study area.

plex risk assessments and accelerate findings (Ding and Tian, 2013). There is no unified criterion for disaster evaluation zoning, and the equal interval method is one of the methods to express the results more intuitively (Hu et al., 2011; Jin and Meng, 2011; Wang et al., 2011). The susceptibility and vulnerability degrees were distinguished using the equal interval method, and four risk grades were then automatically generated. Where the comprehensive risk assessment value was within 0 to 0.0625 , the corresponding risk grade was Grade I; the corresponding risk grades with the values of 0.0625 to $0.25,0.25$ to 0.5625 and 0.5625 to 1.0 were Grade II, III and IV, respectively. The risk grade of each section of the pipeline within the research area is shown in Fig. 7.

The number of sections with a high-risk grade was 33, which accounted for $18.33 \%$ of all pipeline sections and represented $16.57 \%$ of the total pipeline length of $13461 \mathrm{~km}$. There were four sections with extremely high-risk grade, which accounted for $2.22 \%$ of all sections and represented $3.31 \%$ of the total pipeline length of $2.538 \mathrm{~km}$. The section number and the length of the pipelines lying in high-risk (III) and extremely high-risk (IV) areas accounted for $20 \%$ of the total pipeline length, and the risk grade of pipelines inside Qingchuan and Jian'ge County was relatively high.

\subsection{Analysis of risk assessment results}

Large or huge landslides were common in areas that we categorized as extremely high risk, which we defined as those that were geologically evolving or had experienced obvious deformations within the last 2 years with cracks that are still visible. These pipelines were subject to dangers at any time,

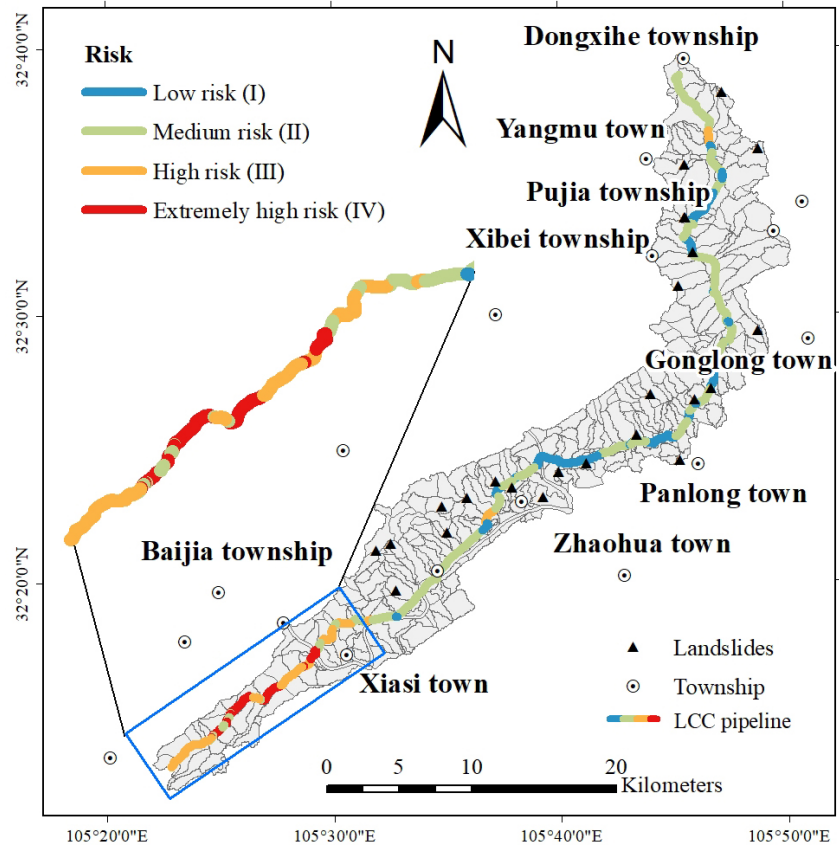

Figure 7. Pipeline risk map of study area.

as the pipelines within the areas prone to landslides were found to contain many defects or extensive damage. These areas also posed considerable threats; for example, pipeline ruptures or breaks could lead to leakages or serious deformations that cause transportation failure. Because these are unacceptable events, risk prevention and control measures must be taken as soon as possible. Pipelines with extremely high risk were mainly distributed in the following areas: (1) Xiasi village in Xiasi County (pipe no. K628-K630) and (2) Shiweng village-Maliu village of Xiasi County (pipe no. K635K637). This section lay in the south of the research area, with an altitude of 500 to $750 \mathrm{~m}$. Here, the slope conditions affected the distribution of groundwater pore pressure and the physical and mechanical characteristics of the rock and soil in three areas: vegetation cover, evaporation and slope erosion. Ultimately, these three factors affected slope stability (Luo and Tan, 2011). Vertical and horizontal ravines were also seen in this section, with a relative height difference greater than $100 \mathrm{~m}$ and slopes between 15 to $35^{\circ}$. Slope degrees with obvious changes had a great influence on slope stability (Chang and Kim, 2004; Hu et al., 2015). The exposed rocks in this area were mainly shale and belonged to the sliding-prone rock group. Rock type and interlayer structure were found to be important internal indicators that a landslide could occur (Guzzetti et al., 1996; Xiang et al., 2010; Xin et al., 2009). The distance between the fault and the pipeline in the section was about $2 \mathrm{~km}$ with a NDVI of about 0.75 and MAP of about $970 \mathrm{~mm}$. Faulted zones and nearby rock and earth masses that were destroyed in a geologic event reduced the integrity of a slope, and the faults and 
important groundwater channels could also cause deformation and damage to a slope (Liu, 2009). The pipelines in these areas exhibited many defects. Most pipelines passed through the slope in an inclined or horizontal way, an attribute that typically increased the risk of a landslide occurring.

In high-risk areas, small or moderate landslides commonly occurred in areas that we have categorized as high risk. They were in the process of deformation, or had obvious deformation recently (within 2 years), such as cracks, subsidence, or tympanites on the landslide, and, in some cases, even shear. The pipelines in these areas had defects and were buried at a shallow depth. If a landslide occurred in this pipeline area, it could cause pipe suspension, floating and damage. It could also contribute to a small to moderate leakage of the multiple petroleum products, such as gasoline, diesel and kerosene. However, damaged pipes can be welded or repaired. Monitoring is critical in high-risk areas. In our study, the pipeline high-risk area was defined as the following areas: (1) Xiasi town-Xiasi village-Shiweng village (pipe no. K622-K633) and (2) Xiasi town-Maliu village-Jinzishan Xiangdasang village (pipe no. K635-K642). This area was located south of the pipe, which was buried in the study area. The altitude of the study area was between 450 and $800 \mathrm{~m}$, the relative elevation difference was over $100 \mathrm{~m}$ and the slope was between 15 and $40^{\circ}$. Most of the outcrops in this area were quartz sandstone, which belongs to the easy-sliding rock group. The pipes in this area were about $2.5 \mathrm{~km}$ away from faults. The NDVI was about 0.6 to 0.8 , and MAP was about $970 \mathrm{~nm}$. Pipes showed many defects, most of them either crossing the slope or lying in the center of slope. All of the above factors provided sufficient conditions for the formation of landslide.

In the medium-risk areas, only small landslides were found to occur, and we observed no sign of deformation. But through the analysis of geological structure, topography and landform, we found the area to demonstrate a tendency for developing landslides. The pipes in this risk area exhibited almost no faults and were buried deep beneath the ground. However, under bad conditions, the landslides in these areas could also affect the pipes' safety, causing the pipes to become exposed or deformed. These areas need simple monitoring. For our study, medium-risk areas were defined as follows: (1) Sanlong village of Dongxihe township-Panlong town-Dongsheng village (pipe no. K559-K593). (2) Panlong town-Qinlao village-Wu'ai village (pipe no. K595-K597). (3) Baolun town-Laolin'gou village-Xiasi town-Youyu village (pipe no. K599-K630).

In the low-risk areas, landslides did not occur under ordinary conditions, but they could occur if a strong earthquake hit or if the area experienced continuous or heavy rain. The pipes in low-risk areas showed no defects and were buried very deep. They were also located far away from areas affected by landslides. Therefore, landslides in these areas caused no obvious damage to the pipes and few threatened the safety of pipes. However, regular inspection is necessary to ensure that the pipes continue to operate safely.
Table 5. Number and distances of pipeline of four risk grades.

\begin{tabular}{lrrrr}
\hline Pipeline risk & $\begin{array}{r}\text { Number of } \\
\text { pipelines }\end{array}$ & $\begin{array}{r}\text { Percen- } \\
\text { tage }(\%)\end{array}$ & $\begin{array}{r}\text { Area } \\
\left(\mathrm{km}^{2}\right)\end{array}$ & $\begin{array}{r}\text { Percen- } \\
\text { tage }(\%)\end{array}$ \\
\hline Low (I) & 37 & 20.56 & 14.469 & 17.81 \\
Medium (II) & 106 & 58.89 & 50.757 & 62.49 \\
High (III) & 33 & 18.33 & 13.461 & 16.57 \\
Extremely (IV) & 4 & 2.22 & 2.538 & 3.13 \\
Total & 180 & 100 & 81.225 & 100 \\
\hline
\end{tabular}

The low-risk areas were defined as follows: (1) Panlong town-Dongsheng village-Qinlao village (pipe no. K591K597) and (2) Baolun town-Xiaojia village-Baolun townLaolin'gou village (pipe no. K599-K608).

Through comprehensive analysis of each risk level area, we compiled a list of pipeline landslide risks (Table 6). This list describes each landslide risk level in four respects: pipeline risk, landslide susceptibility, pipeline vulnerability and risk control measures.

The main purpose of this study was to provide managers and planners a comprehensive assessment of landslide risk in areas containing pipelines. The results offer information on the possibility of failure of slopes. The landslide susceptibility maps could help planners reorganize and plan future pipeline construction. Pipeline vulnerability maps could assist engineers in pipeline maintenance operations. Based on this final risk map, managers and engineers can then make decisions and formulate prescriptions that will have highly predictable results for safely transporting petroleum products, relocating settlements and significantly reducing the risk of any adverse effects.

Future research could explore detailed comparison of different methods and recommend one or more optimal approaches. Moreover, This study shows that landslide risk assessments can be performed with a minimal number of relatively easy to obtain datasets. We advocate establishing a database with assessment parameters similar to the one described by this study to construct dynamic landslide risk assessment models.

\section{Conclusions}

The faults inherent to traditional landslide risk assessments include excessive human influence, failure of pipeline vulnerability assessments to consider the interaction between landslide disaster and pipeline ontology, and the low quantification degree of risk assessment results.

Taking the Guangyuan section $(82 \mathrm{~km})$ of the LCC oil and gas pipeline as an example, we used GIS and RS technology to establish a regional landslide susceptibility assessment model based on the LM-BP neural network. We determined that there were 112 and 108 slopes in high-susceptibility and extremely high-susceptibility areas that accounted for 
Table 6. Description of pipeline risk level.

\begin{tabular}{|c|c|c|c|c|}
\hline $\begin{array}{l}\text { Pipeline } \\
\text { risk }\end{array}$ & $\begin{array}{l}\text { Landslide } \\
\text { susceptibility }\end{array}$ & Vulnerability & Risk & $\begin{array}{l}\text { Control } \\
\text { measures }\end{array}$ \\
\hline Low (I) & $\begin{array}{l}\text { The landslide will not hap- } \\
\text { pen under ordinary con- } \\
\text { ditions, but it will oc- } \\
\text { cur when strong earth- } \\
\text { quakes, long-lasting con- } \\
\text { tinuous rain or extremely } \\
\text { heavy rain occur as well. }\end{array}$ & $\begin{array}{l}\text { The pipes in low-risk ar- } \\
\text { eas have no defects and are } \\
\text { buried very deeply. Mean- } \\
\text { while, they are far away } \\
\text { from the area affected by } \\
\text { landslides. }\end{array}$ & $\begin{array}{l}\text { Landslides cause no obvi- } \\
\text { ous damage to the pipes } \\
\text { and few threats to pipe } \\
\text { safety. }\end{array}$ & $\begin{array}{l}\text { Regular } \\
\text { inspection }\end{array}$ \\
\hline Medium (II) & $\begin{array}{l}\text { Small landslides (volume } \\
\text { of less than } 100000 \mathrm{~m}^{3} \text { ) } \\
\text { mainly occur with no } \\
\text { signs of deformation, but } \\
\text { through analyzing geolog- } \\
\text { ical structures, topography } \\
\text { and landforms a tendency } \\
\text { for landslides is found. }\end{array}$ & $\begin{array}{l}\text { The pipes have almost } \\
\text { no faults and are buried } \\
\text { deeply. However, under } \\
\text { bad conditions, landslides } \\
\text { may also affect pipe safety. }\end{array}$ & $\begin{array}{l}\text { The landslide may cause } \\
\text { the pipes to become ex- } \\
\text { posed or deformed. }\end{array}$ & $\begin{array}{l}\text { Simple } \\
\text { monitoring }\end{array}$ \\
\hline High (III) & $\begin{array}{l}\text { Landslides are mostly } \\
\text { small to moderate (volume } \\
\text { between } 100000 \text { and } \\
1{\text { million } \mathrm{m}^{3} \text { ), and they are }}_{\text {in deformations or have }} \\
\text { recently had obvious de- } \\
\text { formation, such as cracks, } \\
\text { subsidence, or tympanites } \\
\text { on the landslide, and, in } \\
\text { some cases, even shear }\end{array}$ & $\begin{array}{l}\text { The pipeline has defects } \\
\text { and is buried shallowly. } \\
\text { Once landslides occur in } \\
\text { the pipeline area, pipe } \\
\text { safety will be threatened. }\end{array}$ & $\begin{array}{l}\text { The safety of pipeline will } \\
\text { be threatened and may } \\
\text { suffer from pipe suspen- } \\
\text { sion, floating and damage, } \\
\text { etc. Therefore, it will con- } \\
\text { tribute to a small amount } \\
\text { of petroleum product leak- } \\
\text { age. Fortunately, the pipe } \\
\text { can be welded or repaired. }\end{array}$ & $\begin{array}{l}\text { Intensive } \\
\text { monitoring }\end{array}$ \\
\hline $\begin{array}{l}\text { Extremely } \\
\text { high (IV) }\end{array}$ & $\begin{array}{l}\text { Large (volume between } \\
1 \text { million and } 10 \text { mil- } \\
\text { lion } \mathrm{m}^{3} \text { ) or huge (volume } \\
\text { greater than } 10 \text { million } \mathrm{m}^{3} \text { ) } \\
\text { landslides are common in } \\
\text { the areas with extremely } \\
\text { high risk, which are chang- } \\
\text { ing or have experienced } \\
\text { obvious deformation re- } \\
\text { cently with visible cracks. }\end{array}$ & $\begin{array}{l}\text { The pipelines are subject } \\
\text { to dangers at any time as } \\
\text { the pipelines within the } \\
\text { area prone to landslides } \\
\text { have been observed as hav- } \\
\text { ing many defects or a lot of } \\
\text { damage. }\end{array}$ & $\begin{array}{l}\text { There are extreme dan- } \\
\text { gers, for example pipeline } \\
\text { rupture or break, and these } \\
\text { may lead to consider- } \\
\text { able leakage of multiple } \\
\text { petroleum products or } \\
\text { serious deformation and } \\
\text { even interruption of oil } \\
\text { and gas transportation. }\end{array}$ & $\begin{array}{l}\text { Prevention and } \\
\text { control measures } \\
\text { should be taken as } \\
\text { soon as possible. }\end{array}$ \\
\hline
\end{tabular}

$33.18 \%$ and $40.46 \%$ of the total area of the study area, respectively. Then, we established the model of pipeline vulnerability evaluation based on the entropy weight method by combining the pipeline body and the environmental information. The number and length of pipe segments in the highly vulnerable (III) and extremely vulnerable areas (IV) accounted for about $12 \%$ of the total. Finally, based on the susceptibility assessment and the vulnerability assessment, we completed the risk assessment and risk division of the oil pipeline, thus forming a geological disaster risk assessment model and a method for oil pipeline and landslide risk assessment. The risk assessment results demonstrated that the number and length of high-susceptibility and extremely highsusceptibility pipeline segments represented $20 \%$ of the to- tal. Similarly, the pipeline risk within Qingchuan and Jian'ge counties was relatively high. Our pipeline landslide risk assessment has laid a foundation for the future study of pipeline safety management and pipeline failure consequence loss assessment.

Data availability. DEM data can be downloaded from the Geospatial Data Cloud (http://www.gscloud.cn/, last access: October 2016). Precipitation data (dataset of annual surface observation values in China between the years 1981 and 2010) are provided by China Meteorological Administration (http://data.cma.cn/, last access: January 2017). Geological maps, landslide data and pipeline mileage data can be requested by email from the author at neu_xjn@163.com. 


\section{Appendix A}

Table A1. Classification of landslide susceptibility grade corresponding to different intervals.

\begin{tabular}{|c|c|c|c|c|}
\hline Factor & Indicators & Interval & $\begin{array}{l}\text { Susceptibility degree } \\
\text { monotonicity }\end{array}$ & Susceptibility level \\
\hline \multirow{5}{*}{ Landform } & Elevation & $\begin{array}{l}{[1000, \text { highest }]} \\
{[\text { Lowest, 600) }} \\
{[800,1000)} \\
{[600,700) \cup[700,800)}\end{array}$ & $\begin{array}{l}\text { Decreasing } \\
\text { Increasing } \\
\text { Decreasing } \\
\text { Increasing, decreasing }\end{array}$ & $\begin{array}{l}\text { Low susceptibility (I) } \\
\text { Medium susceptibility (II) } \\
\text { High susceptibility (III) } \\
\text { Extremely high susceptibility (IV) }\end{array}$ \\
\hline & Slope & $\begin{array}{l}{[60,90)} \\
{[0,15)} \\
{[30,60)} \\
{[15,20) \cup[20,30)}\end{array}$ & $\begin{array}{l}\text { Decreasing } \\
\text { Increasing } \\
\text { Decreasing } \\
\text { Increasing, decreasing }\end{array}$ & $\begin{array}{l}\text { Low susceptibility (I) } \\
\text { Medium susceptibility (II) } \\
\text { High susceptibility (III) } \\
\text { Extremely high susceptibility (IV) }\end{array}$ \\
\hline & Aspect & $\begin{array}{l}{[0,45) \cup[270,360)} \\
{[225,270) \cup[45,90)} \\
{[90,135) \cup[180,225)} \\
{[135,157.5) \cup[157.5,180)}\end{array}$ & $\begin{array}{l}\text { Increasing, decreasing } \\
\text { Decreasing, increasing } \\
\text { Increasing, decreasing } \\
\text { Increasing, decreasing }\end{array}$ & $\begin{array}{l}\text { Low susceptibility (I) } \\
\text { Medium susceptibility (II) } \\
\text { High susceptibility (III) } \\
\text { Extremely high susceptibility (IV) }\end{array}$ \\
\hline & Height difference & $\begin{array}{l}{[\text { Lowest, 100) }} \\
{[900, \text { highest }] \cup[100,200)} \\
{[600,900) \cup[200,300)} \\
{[300,450) \cup[450,600)}\end{array}$ & $\begin{array}{l}\text { Increasing } \\
\text { Decreasing, increasing } \\
\text { Decreasing, increasing } \\
\text { Increasing, decreasing } \\
\end{array}$ & $\begin{array}{l}\text { Low susceptibility (I) } \\
\text { Medium susceptibility (II) } \\
\text { High susceptibility (III) } \\
\text { Extremely high susceptibility (IV) }\end{array}$ \\
\hline & $\begin{array}{l}\text { Topographic profile } \\
\text { curvature }\end{array}$ & $\begin{array}{l}{[\text { Lowest, }-0.025)} \\
{[0.025, \text { highest }]} \\
{[-0.025,-0.01) \cup[0.01,0.025)} \\
{[-0.01,0) \cup[0,0.01)}\end{array}$ & $\begin{array}{l}\text { Increasing } \\
\text { Decreasing } \\
\text { Increasing, decreasing } \\
\text { Increasing, decreasing }\end{array}$ & $\begin{array}{l}\text { Low susceptibility (I) } \\
\text { Medium susceptibility (II) } \\
\text { High susceptibility (III) } \\
\text { Extremely high susceptibility (IV) }\end{array}$ \\
\hline Land cover & NDVI & $\begin{array}{l}{[-1,0)} \\
{[0,0.6) \cup[0.9,1]} \\
{[0.6,0.7) \cup[0.8,0.9)} \\
{[0.7,0.75) \cup[0.75,0.8)}\end{array}$ & $\begin{array}{l}\text { Increasing } \\
\text { Increasing, decreasing } \\
\text { Increasing, decreasing } \\
\text { Increasing, decreasing }\end{array}$ & $\begin{array}{l}\text { Low susceptibility (I) } \\
\text { Medium susceptibility (II) } \\
\text { High susceptibility (III) } \\
\text { Extremely high susceptibility (IV) }\end{array}$ \\
\hline Precipitation & $\begin{array}{l}\text { Mean annual } \\
\text { precipitation }\end{array}$ & $\begin{array}{l}{[1100, \text { highest })} \\
{[\text { Lowest, } 960)} \\
{[990,1100)} \\
{[960,975) \cup[975,990)}\end{array}$ & $\begin{array}{l}\text { Decreasing } \\
\text { Increasing } \\
\text { Decreasing } \\
\text { Increasing, decreasing }\end{array}$ & $\begin{array}{l}\text { Low susceptibility (I) } \\
\text { Medium susceptibility (II) } \\
\text { High susceptibility (III) } \\
\text { Extremely high susceptibility (IV) }\end{array}$ \\
\hline Geology & $\begin{array}{l}\text { Distance from } \\
\text { the fault }\end{array}$ & $\begin{array}{l}{[20, \text { highest }]} \\
{[15,20)} \\
{[5,15)} \\
{[0,5)}\end{array}$ & $\begin{array}{l}\text { Decreasing } \\
\text { Decreasing } \\
\text { Decreasing } \\
\text { Decreasing }\end{array}$ & $\begin{array}{l}\text { Low susceptibility (I) } \\
\text { Medium susceptibility (II) } \\
\text { High susceptibility (III) } \\
\text { Extremely high susceptibility (IV) }\end{array}$ \\
\hline
\end{tabular}




\section{Appendix B}

Table B1. Standard training sample matrix and standard test sample matrix.

\begin{tabular}{|c|c|c|c|c|c|c|c|c|c|c|c|}
\hline \multirow[t]{2}{*}{ Sample type } & \multirow[t]{2}{*}{ ID } & \multicolumn{9}{|c|}{ Input } & \multirow[t]{2}{*}{ Output } \\
\hline & & Aspect & Slope & Elevation & NDVI & MAP & Height difference & TPC & Distance & Lithology & \\
\hline \multirow{11}{*}{$\begin{array}{l}\text { Training } \\
\text { sample }\end{array}$} & 1 & 0.2 & 89.9 & 438 & -1 & 908.1 & 33 & -0.582 & 25 & 1 & 0 \\
\hline & 50 & 35.2 & 82.8 & 453 & 0 & 912.2 & 79 & -0.456 & 23.47 & 1 & 0.06 \\
\hline & 100 & 297.1 & 75.7 & 469 & 0.88 & 916.3 & 115 & -0.33 & 21.9 & 1 & 0.12 \\
\hline & 150 & 329.3 & 67.6 & 485 & 0.95 & 920.4 & 167 & -0.168 & 20.34 & 1 & 0.19 \\
\hline & 200 & 359.5 & 60 & 499 & 1 & 924.9 & 200 & 0.628 & 18.77 & 1 & 0.25 \\
\hline & 250 & 68.4 & 3.8 & 1293 & 0.73 & 930.4 & 1097 & 0.486 & 17.21 & 2 & 0.31 \\
\hline & 300 & 89.3 & 8.2 & 1206 & 0.65 & 938 & 1039 & 0.326 & 15.64 & 2 & 0.37 \\
\hline & 350 & 246 & 12 & 1102 & 0.56 & 943.6 & 977 & 0.183 & 14.08 & 2 & 0.44 \\
\hline & 400 & 269.3 & 15 & 1002 & 0.5 & 949.8 & 902 & -0.142 & 12.52 & 2 & 0.5 \\
\hline & 450 & 113.4 & 52.9 & 952 & 0.46 & 960.6 & 848 & -0.018 & 10.95 & 3 & 0.56 \\
\hline & 500 & 134.8 & 46.3 & 905 & 0.4 & 972.6 & 757 & -0.012 & 9.39 & 3 & 0.62 \\
\hline \multirow{20}{*}{$\begin{array}{l}\text { Test } \\
\text { sample }\end{array}$} & 1 & 27.2 & 72.3 & 458 & 0.8 & 911.6 & 59 & -0.544 & 25 & 1 & 0 \\
\hline & 2 & 28.5 & 71.6 & 468 & 0.81 & 914.3 & 74 & -0.453 & 23.69 & 1 & 0.06 \\
\hline & 3 & 31.5 & 69.5 & 488 & 0.85 & 915.8 & 86 & -0.381 & 22.37 & 1 & 0.11 \\
\hline & 4 & 37.8 & 66.2 & 490 & 0.86 & 917.1 & 100 & -0.228 & 21.06 & 1 & 0.16 \\
\hline & 5 & 38.6 & 62.1 & 497 & 0.86 & 919.1 & 152 & -0.03 & 19.74 & 1 & 0.22 \\
\hline & 6 & 56.1 & 4.4 & 1141 & 0.7 & 934.2 & 939 & 0.439 & 18.43 & 2 & 0.27 \\
\hline & 7 & 57.3 & 6.6 & 1240 & 0.68 & 939.6 & 941 & 0.429 & 17.11 & 2 & 0.32 \\
\hline & 8 & 65.3 & 9.8 & 1257 & 0.66 & 945.1 & 1124 & 0.413 & 15.79 & 2 & 0.37 \\
\hline & 9 & 68.2 & 11 & 1290 & 0.56 & 948.8 & 1135 & 0.318 & 14.48 & 2 & 0.43 \\
\hline & 10 & 74.7 & 11.9 & 1382 & 0.53 & 949.9 & 1146 & 0.148 & 13.16 & 2 & 0.48 \\
\hline & 11 & 92.4 & 30.4 & 848 & 0.47 & 963.4 & 613 & -0.019 & 11.85 & 3 & 0.53 \\
\hline & 12 & 92.7 & 31.8 & 853 & 0.45 & 970.5 & 683 & -0.016 & 10.53 & 3 & 0.58 \\
\hline & 13 & 101.9 & 44.7 & 900 & 0.45 & 980.5 & 737 & -0.015 & 9.22 & 3 & 0.64 \\
\hline & 14 & 110.1 & 50.9 & 917 & 0.35 & 987 & 817 & -0.015 & 7.9 & 3 & 0.69 \\
\hline & 15 & 115.6 & 57.5 & 933 & 0.32 & 994.2 & 835 & -0.015 & 6.58 & 3 & 0.74 \\
\hline & 16 & 140.6 & 15.6 & 502 & 0.14 & 1001.5 & 245 & 0.019 & 5.27 & 4 & 0.79 \\
\hline & 17 & 155.4 & 20 & 626 & 0.14 & 1002.3 & 256 & 0.008 & 3.95 & 4 & 0.85 \\
\hline & 18 & 157.1 & 24.8 & 690 & 0.08 & 1010.6 & 293 & 0.007 & 2.64 & 4 & 0.9 \\
\hline & 19 & 177.6 & 27.3 & 765 & 0.06 & 1012.7 & 392 & 0.004 & 1.32 & 4 & 0.95 \\
\hline & 20 & 178.3 & 29.6 & 795 & 0.04 & 1022.7 & 446 & 0.001 & 0 & 4 & 1 \\
\hline
\end{tabular}




\section{Appendix C}

Table C1. Test error of LM-BP neural network.

\begin{tabular}{lrrr}
\hline Number & $\begin{array}{r}\text { Expected } \\
\text { value }\end{array}$ & $\begin{array}{r}\text { Network } \\
\text { output }\end{array}$ & Error \\
\hline 1 & 0 & 0.0006 & 0.0006 \\
2 & 0.06 & 0.0548 & -0.0052 \\
3 & 0.11 & 0.1113 & 0.0013 \\
4 & 0.16 & 0.1699 & 0.0099 \\
5 & 0.22 & 0.2302 & 0.0102 \\
6 & 0.27 & 0.2614 & -0.0086 \\
7 & 0.32 & 0.315 & -0.005 \\
8 & 0.37 & 0.3697 & -0.0003 \\
9 & 0.43 & 0.4266 & -0.0034 \\
10 & 0.48 & 0.4899 & 0.0099 \\
11 & 0.53 & 0.5153 & -0.0147 \\
12 & 0.58 & 0.5765 & -0.0035 \\
13 & 0.64 & 0.6405 & 0.0005 \\
14 & 0.69 & 0.701 & 0.011 \\
15 & 0.74 & 0.7523 & 0.0123 \\
16 & 0.79 & 0.8094 & 0.0194 \\
17 & 0.85 & 0.8616 & 0.0116 \\
18 & 0.9 & 0.9155 & 0.0155 \\
19 & 0.95 & 0.9675 & 0.0175 \\
20 & 1 & 1.0173 & 0.0173 \\
\hline
\end{tabular}

\section{Appendix D}

Table D1. Coordinates of the centerline and ancillary facilities of the pipeline. Secrecy regulations regarding geographical coordinate data in the People's Republic of China stipulate that the first three digits of each location's coordinates remain confidential. In this table, this has been represented by ellipses.

\begin{tabular}{|c|c|c|c|c|c|c|c|c|c|}
\hline \multirow[t]{2}{*}{ Point number } & \multirow[t]{2}{*}{ Previous point } & \multirow[t]{2}{*}{ Material } & \multirow{2}{*}{$\begin{array}{r}\text { Diameter } \\
(\mathrm{mm})\end{array}$} & \multirow[t]{2}{*}{ Pressure } & \multirow{2}{*}{$\begin{array}{r}\text { Depth } \\
(\mathrm{m})\end{array}$} & \multicolumn{3}{|c|}{ Coordinate } & \multirow[t]{2}{*}{ Elevation } \\
\hline & & & & & & $X$ & $\mathrm{Y}$ & $\mathrm{H}$ & \\
\hline Marker peg & & - & - & - & - & $\cdots 576.265$ & $\ldots 4357.849$ & 503.877 & - \\
\hline GD1.421 & GD1.420 & Steel & 168 & high & 2.2 & $\ldots 572.111$ & $\ldots 4352.109$ & 504.235 & 502.035 \\
\hline GD1.422 & GD1. & & 168 & high & 1.9 & $\ldots 571.837$ & $\ldots 4336.010$ & 503.866 & 501.966 \\
\hline GD1.423 & GD1.422 & Steel & 168 & high & 2.1 & $\ldots 571.538$ & $\ldots 4319.679$ & 503.694 & 501.594 \\
\hline GD1.424 & GD1.423 & Steel & 168 & high & 2.1 & $\ldots 571.093$ & $\ldots 4308.825$ & 503.510 & 501.410 \\
\hline GD1.425 & GD1.424 & Steel & 168 & high & 2.0 & $\ldots 570.718$ & $\ldots 4288.141$ & 503.733 & 501.733 \\
\hline \multicolumn{2}{|c|}{ Detective pole K566 } & - & - & - & - & $\ldots 575.536$ & $\cdots 4284.069$ & 503.494 & - \\
\hline GD1.426 & GD1.425 & Steel & 168 & high & 2.3 & $\ldots 570.603$ & $\ldots 4275.147$ & & \\
\hline \multicolumn{2}{|c|}{ Mileage peg K566+200 } & - & - & - & - & $\cdots 574.641$ & $\cdots 4258.41$ & 503.224 & - \\
\hline GD1.427 & GD1.426 & Steel & 168 & high & 2.0 & $\cdots 570.222$ & $\ldots 4258.593$ & 503.710 & 501.710 \\
\hline GD1.428 & GD1.427 & Steel & 168 & high & 1.6 & $\ldots 570.090$ & $\ldots 4247.642$ & 503.283 & 501.683 \\
\hline GD1.429 & GD1.428 & Steel & 168 & high & 2.3 & $\cdots 569.458$ & $\ldots 4216.618$ & 502.468 & 500.168 \\
\hline GD1.430 & GD1.429 & Steel & 168 & high & 2.9 & $\ldots 569.043$ & $\ldots 4208.558$ & 504.055 & 501.155 \\
\hline
\end{tabular}




\section{Appendix E}

Table E1. Internal detection data of each pipeline.

\begin{tabular}{|c|c|c|c|c|c|c|}
\hline Feature ID & $\begin{array}{r}\text { Pipe } \\
\text { number }\end{array}$ & $\begin{array}{r}\text { Distance } \\
(\mathrm{m})\end{array}$ & Feature type & Remarks & $\begin{array}{r}\text { Length } \\
(\mathrm{mm})\end{array}$ & $\begin{array}{r}\text { Thickness } \\
(\mathrm{mm})\end{array}$ \\
\hline 1 & 10 & 6.408 & Pipe segment & Spiral weld & 652 & 11.1 \\
\hline 2 & 20 & 7.060 & Pipe segment & - & 1178 & - \\
\hline 3 & 20 & 7.648 & Fixed punctuation point & Valve centerline & - & - \\
\hline 4 & 20 & 7.650 & Valve & Centerline & - & - \\
\hline 5 & 30 & 8.238 & Pipe segment & Spiral weld & 768 & 11.1 \\
\hline 6 & 40 & 9.006 & Pipe segment & - & 2184 & - \\
\hline 7 & 40 & 10.100 & Globular tee & Centerline & - & - \\
\hline 8 & 50 & 11.190 & Pipe segment & Spiral weld & 1700 & 11.1 \\
\hline 9 & 50 & 11.445 & Pit & - & 548 & 11.1 \\
\hline 10 & 60 & 12.890 & Pipe segment & Straight weld & 2342 & 13.6 \\
\hline 11 & 60 & 12.890 & Wall thickness variation & from 11.1 to $13.6 \mathrm{~mm}$ & - & - \\
\hline 13 & 70 & 15.232 & Pipe segment & Spiral weld & 1999 & 11.1 \\
\hline 14 & 70 & 15.232 & Wall thickness variation & From 13.6 to $11.1 \mathrm{~mm}$ & - & - \\
\hline 15 & 80 & 17.231 & Pipe segment & Straight weld & 2352 & 13.4 \\
\hline 16 & 80 & 17.231 & Wall thickness variation & From 11.1 to $13.4 \mathrm{~mm}$ & - & - \\
\hline 18 & 90 & 19.583 & Pipe segment & Spiral weld & 11557 & 11.1 \\
\hline 19 & 90 & 19.583 & Wall thickness variation & From 13.4 to $11.1 \mathrm{~mm}$ & - & - \\
\hline 20 & 90 & 28.060 & Attachments & - & 598 & 11.1 \\
\hline 21 & 100 & 31.140 & Pipe segment & - & 991 & - \\
\hline 22 & 100 & 31.580 & Flange & centerline & - & - \\
\hline 23 & 110 & 32.131 & Pipe segment & Spiral weld & 11660 & 11.1 \\
\hline 24 & 120 & 43.791 & Pipe segment & Spiral weld & 5536 & 11.1 \\
\hline 25 & 130 & 49.327 & Pipe segment & Straight weld & 2213 & 16.2 \\
\hline 26 & 130 & 49.327 & Wall thickness variation & From 11.1 to $16.2 \mathrm{~mm}$ & - & - \\
\hline 28 & 140 & 51.540 & Pipe segment & Spiral weld & 5608 & 11.1 \\
\hline 29 & 140 & 51.540 & Wall thickness variation & From 16.2 to $11.1 \mathrm{~mm}$ & - & - \\
\hline 30 & 150 & 57.148 & Pipe segment & Spiral weld & 9432 & 11.1 \\
\hline
\end{tabular}




\section{Appendix F: Core code of pipeline defect point} coordinate calculating program

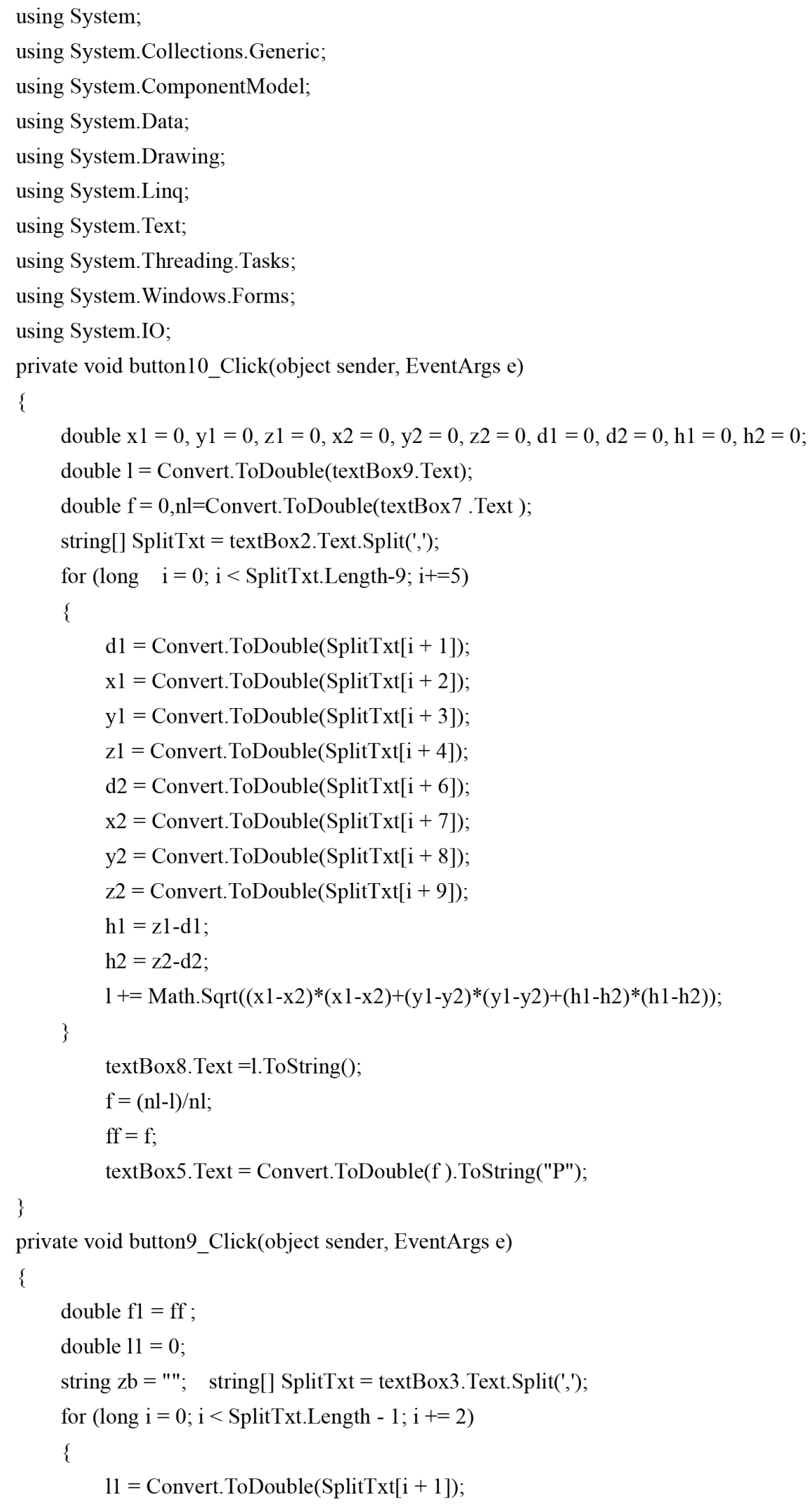


$11+=(-\mathrm{ff}) * 11$

double $\mathrm{x} 1=0, \mathrm{y} 1=0, \mathrm{z} 1=0, \mathrm{x} 2=0, \mathrm{y} 2=0, \mathrm{z} 2=0, \mathrm{~d} 1=0, \mathrm{~d} 2=0, \mathrm{~h} 1=0, \mathrm{~h} 2=0$,

$10=0,12=0$;

double $1=$ Convert. ToDouble $($ textBox9.Text);

double $\mathrm{x}=0, \mathrm{y}=0, \mathrm{~h}=0$;

string[] SplitTxt1 = textBox2.Text.Split(',');

for (long $\mathrm{j}=0 ; \mathrm{j}<$ SplitTxt1.Length $-9 ; \mathrm{j}+=5$ )

\{

$\mathrm{d} l=$ Convert.ToDouble(SplitTxt $1[\mathrm{j}+1])$;

$\mathrm{x} 1=$ Convert.ToDouble(SplitTxt1 $[\mathrm{j}+2])$;

$\mathrm{y} 1=$ Convert.ToDouble(SplitTxt1 $[\mathrm{j}+3])$;

$\mathrm{zl}=$ Convert.ToDouble(SplitTxt1[j +4$])$;

$\mathrm{d} 2=$ Convert.ToDouble(SplitTxt1 $[\mathrm{j}+6])$;

$\mathrm{x} 2=$ Convert.ToDouble(SplitTxt1 $[\mathrm{j}+7])$;

y2 = Convert.ToDouble(SplitTxt $1[j+8])$;

z2 = Convert.ToDouble(SplitTxt1[j +9$])$;

$\mathrm{h} 1=\mathrm{z} 1-\mathrm{d} 1 ; \mathrm{h} 2=\mathrm{z} 2-\mathrm{d} 2 ;$

$10=\operatorname{Math} \cdot \operatorname{Sqrt}((\mathrm{x} 1-\mathrm{x} 2) *(\mathrm{x} 1-\mathrm{x} 2)+(\mathrm{y} 1-\mathrm{y} 2) *(\mathrm{y} 1-\mathrm{y} 2)+(\mathrm{hl}-\mathrm{h} 2) *(\mathrm{hl}-\mathrm{h} 2)) ;$

$1=1+10$;

if $(1-11<0)$

\{

\}

else if $(1-11>0)$

\{

$12=10-(1-11)$

$\mathrm{x}=\mathrm{x} 1+(\mathrm{x} 2-\mathrm{x} 1) * 12 / 10$

$\mathrm{y}=\mathrm{yl}+(\mathrm{y} 2-\mathrm{y} 1) * 12 / 10$

$\mathrm{h}=\mathrm{h} 1+(\mathrm{h} 2-\mathrm{h} 1) * 12 / 10$

string $x x, y y, h h, v$;

$\mathrm{v}=$ SplitTxt $[\mathrm{i}]$;

$\mathrm{xx}=$ Convert.ToDouble $(\mathrm{x}) \cdot$ ToString () ;

yy = Convert.ToDouble(y).ToString();

$\mathrm{hh}=$ Convert. ToDouble(h).ToString();

zb $+=\mathrm{v}+$ ","+ xx + "," + yy + "," + hh +", In";

break;

\}

\}

\}

textBox6.Text $=\mathrm{zb}$;

\} 
Appendix G

Table G1. Pipeline landslide risk assessment results.

\begin{tabular}{|c|c|c|c|c|c|c|c|c|}
\hline FID & Start & Terminus & Susceptibility & $\begin{array}{l}\text { Susceptibility } \\
\text { level }\end{array}$ & Vulnerability & $\begin{array}{l}\text { Vulnerability } \\
\text { level }\end{array}$ & Risk & $\begin{array}{l}\text { Risk } \\
\text { level }\end{array}$ \\
\hline 1 & K558 & $\mathrm{K} 559+446$ & 0.874 & IV & 0.168 & I & 0.147 & II \\
\hline 2 & $\mathrm{~K} 559+446$ & $\mathrm{~K} 563+718$ & 0.874 & IV & 0.178 & I & 0.156 & II \\
\hline 3 & $\mathrm{~K} 563+718$ & $\mathrm{~K} 564+883$ & 0.932 & IV & 0.143 & I & 0.133 & II \\
\hline 4 & $\mathrm{~K} 564+883$ & $\mathrm{~K} 566+90$ & 0.943 & IV & 0.149 & I & 0.141 & II \\
\hline 5 & K566+90 & $\mathrm{K} 567+117$ & 0.943 & IV & 0.280 & II & 0.264 & III \\
\hline 6 & $\mathrm{~K} 567+117$ & $\mathrm{~K} 567+224$ & 0.766 & IV & 0.095 & I & 0.073 & I \\
\hline 7 & $\mathrm{~K} 567+224$ & $\mathrm{~K} 567+384$ & 0.729 & III & 0.117 & I & 0.085 & II \\
\hline 8 & $\mathrm{~K} 567+384$ & $\mathrm{~K} 567+674$ & 0.729 & III & 0.079 & I & 0.058 & I \\
\hline 9 & $\mathrm{~K} 567+674$ & $\mathrm{~K} 567+782$ & 0.729 & III & 0.141 & I & 0.103 & II \\
\hline 10 & $\mathrm{~K} 567+782$ & $\mathrm{~K} 567+846$ & 0.729 & III & 0.066 & I & 0.048 & $\mathrm{I}$ \\
\hline 11 & $\mathrm{~K} 567+846$ & K567+904 & 0.729 & III & 0.097 & I & 0.071 & I \\
\hline 12 & K568+904 & $\mathrm{K} 568+197$ & 0.722 & III & 0.154 & I & 0.111 & II \\
\hline 13 & K568+197 & $\mathrm{K} 568+430$ & 0.763 & IV & 0.144 & I & 0.110 & II \\
\hline 14 & $\mathrm{~K} 569+430$ & K569+419 & 0.739 & III & 0.186 & I & 0.137 & II \\
\hline 15 & K569+419 & $\mathrm{K} 569+443$ & 0.739 & III & 0.141 & I & 0.104 & II \\
\hline 16 & $\mathrm{~K} 569+443$ & $\mathrm{~K} 569+467$ & 0.739 & III & 0.107 & I & 0.079 & II \\
\hline 17 & K569+467 & $\mathrm{K} 569+578$ & 0.739 & III & 0.121 & I & 0.089 & II \\
\hline 18 & $\mathrm{~K} 569+578$ & K569+920 & 0.739 & III & 0.107 & I & 0.079 & II \\
\hline 19 & $\mathrm{~K} 571+920$ & $\mathrm{~K} 571+123$ & 0.736 & III & 0.127 & I & 0.093 & II \\
\hline 20 & $\mathrm{~K} 571+123$ & $\mathrm{~K} 571+982$ & 0.799 & IV & 0.109 & I & 0.087 & II \\
\hline 21 & $\mathrm{~K} 572+982$ & $\mathrm{~K} 572+729$ & 0.753 & IV & 0.090 & I & 0.068 & I \\
\hline 22 & $\mathrm{~K} 573+729$ & $\mathrm{~K} 573+548$ & 0.802 & IV & 0.094 & I & 0.075 & I \\
\hline 23 & K574+548 & $\mathrm{K} 574+249$ & 0.805 & IV & 0.084 & I & 0.068 & I \\
\hline 24 & $\mathrm{~K} 574+249$ & $\mathrm{~K} 574+525$ & 0.805 & IV & 0.150 & I & 0.121 & II \\
\hline 25 & $\mathrm{~K} 575+525$ & $\mathrm{~K} 575+538$ & 0.805 & IV & 0.115 & I & 0.093 & II \\
\hline 26 & $\mathrm{~K} 575+538$ & $\mathrm{~K} 575+600$ & 0.805 & IV & 0.157 & I & 0.126 & II \\
\hline 27 & K576+600 & K576+737 & 0.816 & IV & 0.108 & I & 0.088 & II \\
\hline 28 & $\mathrm{~K} 577+737$ & $\mathrm{~K} 577+120$ & 0.889 & IV & 0.089 & I & 0.079 & I \\
\hline 29 & $\mathrm{~K} 577+120$ & $\mathrm{~K} 577+146$ & 0.889 & IV & 0.094 & I & 0.084 & I \\
\hline 30 & $\mathrm{~K} 577+146$ & $\mathrm{~K} 577+187$ & 0.889 & IV & 0.169 & I & 0.150 & II \\
\hline 31 & $\mathrm{~K} 578+187$ & $\mathrm{~K} 578+571$ & 0.889 & IV & 0.118 & I & 0.105 & II \\
\hline 32 & $\mathrm{~K} 578+571$ & $\mathrm{~K} 578+608$ & 0.889 & IV & 0.095 & I & 0.084 & I \\
\hline 33 & K579+608 & K579+624 & 0.853 & IV & 0.133 & I & 0.113 & II \\
\hline 34 & $\mathrm{~K} 580+624$ & $\mathrm{~K} 580+582$ & 0.871 & IV & 0.156 & I & 0.136 & II \\
\hline 35 & $\mathrm{~K} 581+582$ & $\mathrm{~K} 581+43$ & 0.871 & IV & 0.097 & I & 0.084 & I \\
\hline 36 & $\mathrm{~K} 581+43$ & $\mathrm{~K} 581+273$ & 0.871 & IV & 0.143 & I & 0.125 & II \\
\hline 37 & $\mathrm{~K} 581+273$ & $\mathrm{~K} 581+536$ & 0.880 & IV & 0.125 & I & 0.110 & II \\
\hline 38 & $\mathrm{~K} 581+536$ & $\mathrm{~K} 581+659$ & 0.872 & IV & 0.154 & I & 0.134 & II \\
\hline 39 & K582+659 & $\mathrm{K} 582+263$ & 0.830 & IV & 0.152 & I & 0.126 & II \\
\hline 40 & $\mathrm{~K} 582+263$ & $\mathrm{~K} 582+437$ & 0.830 & IV & 0.116 & I & 0.096 & II \\
\hline 41 & $\mathrm{~K} 583+437$ & $\mathrm{~K} 583+512$ & 0.830 & IV & 0.152 & I & 0.126 & II \\
\hline 42 & $\mathrm{~K} 583+512$ & $\mathrm{~K} 583+693$ & 0.798 & IV & 0.105 & I & 0.084 & II \\
\hline 43 & K583+693 & $\mathrm{K} 583+720$ & 0.740 & III & 0.113 & I & 0.084 & II \\
\hline 44 & $\mathrm{~K} 585+720$ & $\mathrm{~K} 585+55$ & 0.740 & III & 0.178 & I & 0.132 & II \\
\hline 45 & K585+55 & K585+101 & 0.668 & III & 0.196 & I & 0.131 & II \\
\hline 46 & K585+101 & $\mathrm{K} 585+370$ & 0.668 & III & 0.178 & I & 0.119 & II \\
\hline 47 & $\mathrm{~K} 585+370$ & K585+634 & 0.696 & III & 0.190 & I & 0.132 & II \\
\hline 48 & K585+634 & K585+734 & 0.668 & III & 0.116 & I & 0.077 & II \\
\hline 49 & K585+734 & K585+908 & 0.627 & III & 0.198 & I & 0.124 & II \\
\hline 50 & K585+908 & K585+949 & 0.627 & III & 0.168 & I & 0.105 & II \\
\hline
\end{tabular}


Table G1. Continued.

\begin{tabular}{|c|c|c|c|c|c|c|c|c|}
\hline FID & Start & Terminus & Susceptibility & $\begin{array}{l}\text { Susceptibility } \\
\text { level }\end{array}$ & Vulnerability & $\begin{array}{l}\text { Vulnerability } \\
\text { level }\end{array}$ & Risk & $\begin{array}{l}\text { Risk } \\
\text { level }\end{array}$ \\
\hline 51 & K586+949 & K586+782 & 0.627 & III & 0.173 & I & 0.108 & II \\
\hline 52 & K586+782 & K586+805 & 0.627 & III & 0.117 & $\mathrm{I}$ & 0.073 & II \\
\hline 53 & $\mathrm{~K} 587+805$ & $\mathrm{~K} 587+364$ & 0.627 & III & 0.171 & I & 0.107 & II \\
\hline 54 & $\mathrm{~K} 587+364$ & $\mathrm{~K} 587+498$ & 0.618 & III & 0.078 & I & 0.048 & I \\
\hline 55 & K587+498 & K587+794 & 0.618 & III & 0.107 & I & 0.066 & I \\
\hline 56 & K589+794 & K589+251 & 0.618 & III & 0.102 & I & 0.063 & I \\
\hline 57 & K590+251 & K590+757 & 0.618 & III & 0.172 & I & 0.106 & II \\
\hline 58 & K590+757 & $\mathrm{K} 590+780$ & 0.556 & III & 0.153 & I & 0.085 & II \\
\hline 59 & $\mathrm{~K} 590+780$ & $\mathrm{~K} 590+812$ & 0.556 & III & 0.123 & I & 0.068 & II \\
\hline 60 & K591+812 & K591+500 & 0.555 & III & 0.135 & I & 0.075 & II \\
\hline 61 & $\mathrm{~K} 591+500$ & K591+946 & 0.555 & III & 0.087 & I & 0.048 & I \\
\hline 62 & K592+946 & K592+259 & 0.555 & III & 0.107 & I & 0.059 & I \\
\hline 63 & K593+259 & K593+631 & 0.517 & III & 0.152 & I & 0.079 & II \\
\hline 64 & K593+631 & K593+912 & 0.374 & II & 0.153 & I & 0.057 & II \\
\hline 65 & K594+912 & K594+993 & 0.374 & II & 0.150 & I & 0.056 & II \\
\hline 66 & K595+993 & K595+203 & 0.374 & II & 0.076 & I & 0.028 & I \\
\hline 67 & K595+203 & K595+261 & 0.359 & II & 0.114 & I & 0.041 & I \\
\hline 68 & K595+261 & K595+383 & 0.359 & II & 0.099 & I & 0.036 & I \\
\hline 69 & K596+383 & K596+383 & 0.412 & II & 0.278 & II & 0.115 & II \\
\hline 70 & K596+383 & K596+429 & 0.412 & II & 0.107 & I & 0.044 & I \\
\hline 71 & K597+429 & K597+62 & 0.359 & II & 0.121 & I & 0.043 & I \\
\hline 72 & $\mathrm{~K} 597+62$ & K597+200 & 0.412 & II & 0.158 & I & 0.065 & II \\
\hline 73 & K597+200 & $\mathrm{K} 597+345$ & 0.412 & II & 0.133 & I & 0.055 & I \\
\hline 74 & K597+345 & K597+680 & 0.412 & II & 0.273 & II & 0.112 & II \\
\hline 75 & K599+680 & K599+376 & 0.321 & II & 0.461 & II & 0.148 & II \\
\hline 76 & K599+376 & K599+693 & 0.211 & $\mathrm{I}$ & 0.105 & $\mathrm{I}$ & 0.022 & I \\
\hline 77 & K600+693 & $\mathrm{K} 600+188$ & 0.211 & I & 0.179 & I & 0.038 & I \\
\hline 78 & K600+188 & $\mathrm{K} 600+353$ & 0.106 & I & 0.172 & I & 0.018 & I \\
\hline 79 & $\mathrm{~K} 601+353$ & K601+369 & 0.106 & I & 0.264 & II & 0.028 & I \\
\hline 80 & K602+369 & K602+495 & 0.099 & I & 0.190 & $\mathrm{I}$ & 0.019 & I \\
\hline 81 & K603+495 & K603+131 & 0.067 & I & 0.436 & II & 0.029 & I \\
\hline 82 & K603+131 & K603+551 & 0.099 & I & 0.144 & I & 0.014 & I \\
\hline 83 & K604+551 & K604+321 & 0.104 & I & 0.253 & II & 0.026 & I \\
\hline 84 & K604+321 & K604+976 & 0.099 & I & 0.102 & I & 0.010 & I \\
\hline 85 & K605+976 & K605+735 & 0.178 & I & 0.372 & II & 0.066 & II \\
\hline 86 & K606+735 & K606+368 & 0.236 & I & 0.637 & III & 0.150 & II \\
\hline 87 & K606+368 & K606+838 & 0.236 & I & 0.127 & I & 0.030 & I \\
\hline 88 & K607+838 & K607+596 & 0.323 & II & 0.407 & II & 0.131 & II \\
\hline 89 & K608+596 & $\mathrm{K} 608+20$ & 0.323 & II & 0.163 & $\mathrm{I}$ & 0.053 & II \\
\hline 90 & K608+20 & K608+287 & 0.323 & II & 0.145 & I & 0.047 & I \\
\hline 91 & K608+287 & K608+546 & 0.346 & II & 0.084 & I & 0.029 & I \\
\hline 92 & K608+546 & K608+583 & 0.406 & II & 0.215 & I & 0.087 & II \\
\hline 93 & K608+583 & K608+835 & 0.406 & II & 0.291 & II & 0.118 & II \\
\hline 94 & K609+835 & K609+565 & 0.442 & II & 0.279 & II & 0.123 & II \\
\hline 95 & K610+565 & K610+564 & 0.442 & II & 0.403 & II & 0.178 & II \\
\hline 96 & K610+564 & K610+945 & 0.442 & II & 0.453 & II & 0.200 & II \\
\hline 97 & K611+945 & $\mathrm{K} 611+89$ & 0.482 & II & 0.117 & I & 0.056 & I \\
\hline 98 & $\mathrm{~K} 611+89$ & K611+691 & 0.501 & III & 0.138 & I & 0.069 & II \\
\hline 99 & K612+691 & $\mathrm{K} 612+413$ & 0.501 & III & 0.175 & I & 0.088 & II \\
\hline 100 & $\mathrm{~K} 613+413$ & K613+269 & 0.501 & III & 0.163 & I & 0.082 & II \\
\hline 101 & K613+269 & K613+442 & 0.502 & III & 0.166 & I & 0.083 & II \\
\hline 102 & K614+442 & K614+83 & 0.502 & III & 0.354 & II & 0.178 & II \\
\hline 103 & K614+83 & K614+980 & 0.502 & III & 0.263 & II & 0.132 & II \\
\hline 104 & K615+980 & K615+218 & 0.601 & III & 0.153 & I & 0.092 & II \\
\hline
\end{tabular}


Table G1. Continued.

\begin{tabular}{|c|c|c|c|c|c|c|c|c|}
\hline FID & Start & Terminus & Susceptibility & $\begin{array}{l}\text { Susceptibility } \\
\text { level }\end{array}$ & Vulnerability & $\begin{array}{l}\text { Vulnerability } \\
\text { level }\end{array}$ & Risk & $\begin{array}{l}\text { Risk } \\
\text { level }\end{array}$ \\
\hline 105 & K615+218 & K615+388 & 0.601 & III & 0.143 & I & 0.086 & II \\
\hline 106 & K616+388 & K616+87 & 0.635 & III & 0.126 & I & 0.080 & II \\
\hline 107 & K616+87 & K616+300 & 0.556 & III & 0.144 & I & 0.080 & II \\
\hline 108 & K616+300 & $\mathrm{K} 616+460$ & 0.505 & III & 0.269 & II & 0.136 & II \\
\hline 109 & $\mathrm{~K} 617+460$ & K617+715 & 0.505 & III & 0.172 & I & 0.087 & II \\
\hline 110 & K617+715 & K617+827 & 0.505 & III & 0.255 & II & 0.129 & II \\
\hline 111 & K618+827 & K618+28 & 0.556 & III & 0.170 & I & 0.095 & II \\
\hline 112 & K618+28 & K618+687 & 0.556 & III & 0.313 & II & 0.174 & II \\
\hline 113 & K620+687 & K620+78 & 0.556 & III & 0.188 & I & 0.105 & II \\
\hline 114 & K620+78 & K620+298 & 0.425 & II & 0.196 & I & 0.083 & II \\
\hline 115 & K621+298 & K621+509 & 0.576 & III & 0.223 & I & 0.128 & II \\
\hline 116 & K621+509 & K621+611 & 0.425 & II & 0.107 & I & 0.045 & I \\
\hline 117 & K622+611 & $\mathrm{K} 622+10$ & 0.425 & II & 0.262 & II & 0.111 & II \\
\hline 118 & $\mathrm{~K} 622+10$ & $\mathrm{~K} 622+86$ & 0.425 & II & 0.122 & I & 0.052 & I \\
\hline 119 & K622+86 & K622+539 & 0.693 & III & 0.178 & I & 0.123 & II \\
\hline 120 & K622+539 & K622+897 & 0.634 & III & 0.549 & III & 0.348 & III \\
\hline 121 & K623+897 & $\mathrm{K} 623+36$ & 0.634 & III & 0.535 & III & 0.339 & III \\
\hline 122 & K623+36 & K623+794 & 0.693 & III & 0.145 & I & 0.100 & II \\
\hline 123 & K624+794 & K624+866 & 0.693 & III & 0.310 & II & 0.215 & II \\
\hline 124 & K625+866 & K625+242 & 0.796 & IV & 0.137 & I & 0.109 & II \\
\hline 125 & $\mathrm{~K} 627+242$ & $\mathrm{~K} 627+60$ & 0.859 & IV & 0.452 & II & 0.388 & III \\
\hline 126 & $\mathrm{~K} 627+60$ & K627+162 & 0.859 & IV & 0.193 & I & 0.166 & II \\
\hline 127 & K627+162 & $\mathrm{K} 627+313$ & 0.859 & IV & 0.166 & I & 0.143 & II \\
\hline 128 & $\mathrm{~K} 627+313$ & $\mathrm{~K} 627+700$ & 0.783 & IV & 0.167 & I & 0.131 & II \\
\hline 129 & K628+700 & K628+146 & 0.908 & IV & 0.501 & III & 0.455 & III \\
\hline 130 & K628+146 & K628+196 & 0.908 & IV & 0.139 & $\mathrm{I}$ & 0.126 & II \\
\hline 131 & K628+196 & K628+610 & 0.908 & IV & 0.631 & III & 0.573 & IV \\
\hline 132 & K629+610 & K629+355 & 0.787 & IV & 0.369 & II & 0.290 & III \\
\hline 133 & K629+355 & K629+525 & 0.787 & IV & 0.729 & III & 0.574 & IV \\
\hline 134 & K629+525 & K629+570 & 0.787 & IV & 0.252 & II & 0.198 & II \\
\hline 135 & K629+570 & K629+620 & 0.787 & IV & 0.465 & II & 0.366 & III \\
\hline 136 & K630+620 & K630+348 & 0.787 & IV & 0.286 & II & 0.225 & II \\
\hline 137 & K630+348 & K630+956 & 0.892 & IV & 0.389 & II & 0.347 & III \\
\hline 138 & K631+956 & K631+116 & 0.886 & IV & 0.423 & II & 0.375 & III \\
\hline 139 & K631+116 & K631+528 & 0.805 & IV & 0.513 & III & 0.413 & III \\
\hline 140 & K633+528 & $\mathrm{K} 633+435$ & 0.805 & IV & 0.568 & III & 0.457 & III \\
\hline 141 & K635+435 & K635+302 & 0.933 & IV & 0.625 & III & 0.583 & IV \\
\hline 142 & K635+302 & K635+326 & 0.884 & IV & 0.611 & III & 0.540 & III \\
\hline 143 & K635+326 & K635+359 & 0.884 & IV & 0.441 & II & 0.390 & III \\
\hline 144 & K635+359 & K635+368 & 0.884 & IV & 0.194 & I & 0.171 & II \\
\hline 145 & K635+368 & K635+530 & 0.884 & IV & 0.374 & II & 0.331 & III \\
\hline 146 & K635+530 & K635+604 & 0.884 & IV & 0.307 & II & 0.271 & III \\
\hline 147 & K635+604 & K635+850 & 0.805 & IV & 0.377 & II & 0.303 & III \\
\hline 148 & K635+850 & K635+943 & 0.805 & IV & 0.234 & I & 0.188 & II \\
\hline 149 & K635+943 & K635+972 & 0.805 & IV & 0.139 & I & 0.112 & II \\
\hline 150 & K635+972 & K635+974 & 0.805 & IV & 0.121 & I & 0.097 & II \\
\hline 151 & K635+974 & K635+990 & 0.805 & IV & 0.138 & I & 0.111 & II \\
\hline 152 & K636+990 & K636+152 & 0.933 & IV & 0.598 & III & 0.558 & III \\
\hline 153 & K636+152 & K636+159 & 0.933 & IV & 0.157 & I & 0.146 & II \\
\hline 154 & K636+159 & K636+320 & 0.884 & IV & 0.579 & III & 0.512 & III \\
\hline 155 & K636+320 & K636+427 & 0.884 & IV & 0.166 & I & 0.147 & II \\
\hline 156 & K636+427 & K636+517 & 0.884 & IV & 0.124 & I & 0.110 & II \\
\hline 157 & K636+517 & K636+806 & 0.834 & IV & 0.663 & III & 0.553 & III \\
\hline 158 & K636+806 & K636+893 & 0.834 & IV & 0.794 & IV & 0.662 & IV \\
\hline
\end{tabular}


Table G1. Continued.

\begin{tabular}{lllllllll}
\hline FID & Start & Terminus & Susceptibility & $\begin{array}{l}\text { Susceptibility } \\
\text { level }\end{array}$ & Vulnerability & $\begin{array}{l}\text { Vulnerability } \\
\text { level }\end{array}$ & $\begin{array}{c}\text { Risk } \\
\text { Risk } \\
\text { level }\end{array}$ \\
\hline 159 & K637+893 & K637+57 & 0.834 & IV & 0.519 & III & 0.433 & III \\
160 & K637+57 & K637+109 & 0.834 & IV & 0.542 & III & 0.452 & III \\
161 & K637+109 & K637+181 & 0.834 & IV & 0.111 & I & 0.093 & II \\
162 & K637+181 & K637+332 & 0.834 & IV & 0.127 & I & 0.106 & II \\
163 & K638+332 & K638+87 & 0.834 & IV & 0.608 & III & 0.507 & III \\
164 & K638+87 & K638+140 & 0.834 & IV & 0.157 & I & 0.131 & II \\
165 & K638+140 & K638+193 & 0.767 & IV & 0.682 & III & 0.523 & III \\
166 & K638+193 & K638+199 & 0.767 & IV & 0.188 & I & 0.144 & II \\
167 & K638+199 & K638+226 & 0.767 & IV & 0.126 & I & 0.097 & II \\
168 & K638+226 & K638+368 & 0.767 & IV & 0.532 & III & 0.408 & III \\
169 & K638+368 & K638+409 & 0.767 & IV & 0.604 & III & 0.463 & III \\
170 & K638+409 & K638+432 & 0.767 & IV & 0.205 & I & 0.157 & II \\
171 & K638+432 & K638+444 & 0.767 & IV & 0.525 & III & 0.403 & III \\
172 & K638+444 & K638+676 & 0.767 & IV & 0.173 & I & 0.133 & II \\
173 & K638+676 & K638+837 & 0.767 & IV & 0.479 & II & 0.367 & III \\
174 & K639+837 & K639+266 & 0.744 & III & 0.483 & II & 0.359 & III \\
175 & K639+266 & K639+339 & 0.744 & III & 0.427 & II & 0.318 & III \\
176 & K639+339 & K639+435 & 0.744 & III & 0.549 & III & 0.408 & III \\
177 & K639+435 & K639+562 & 0.631 & III & 0.324 & II & 0.204 & II \\
178 & K640+562 & K640+63 & 0.607 & III & 0.476 & II & 0.289 & III \\
179 & K641+63 & K641+600 & 0.607 & III & 0.604 & III & 0.367 & III \\
180 & K642+600 & K642+225 & 0.607 & III & 0.461 & II & 0.280 & III \\
\hline
\end{tabular}


Appendix H: Field environment of study area

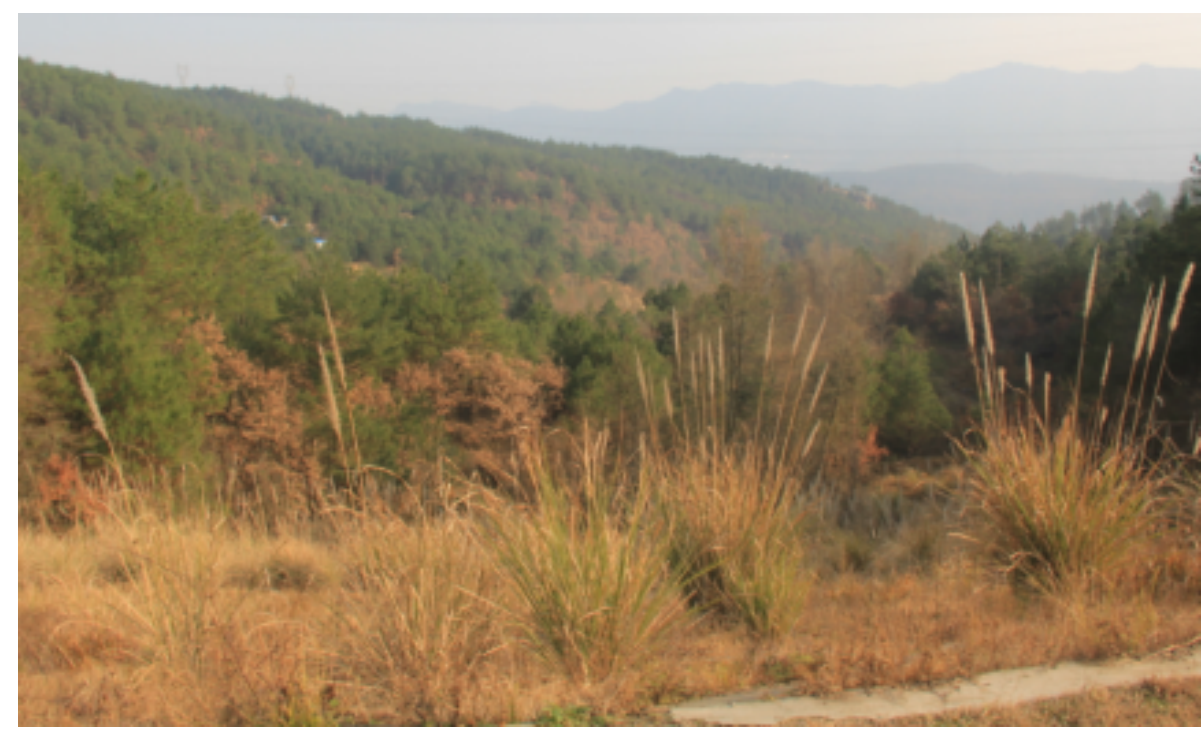

Figure H1. Vegetation distribution in a watershed in the study area.

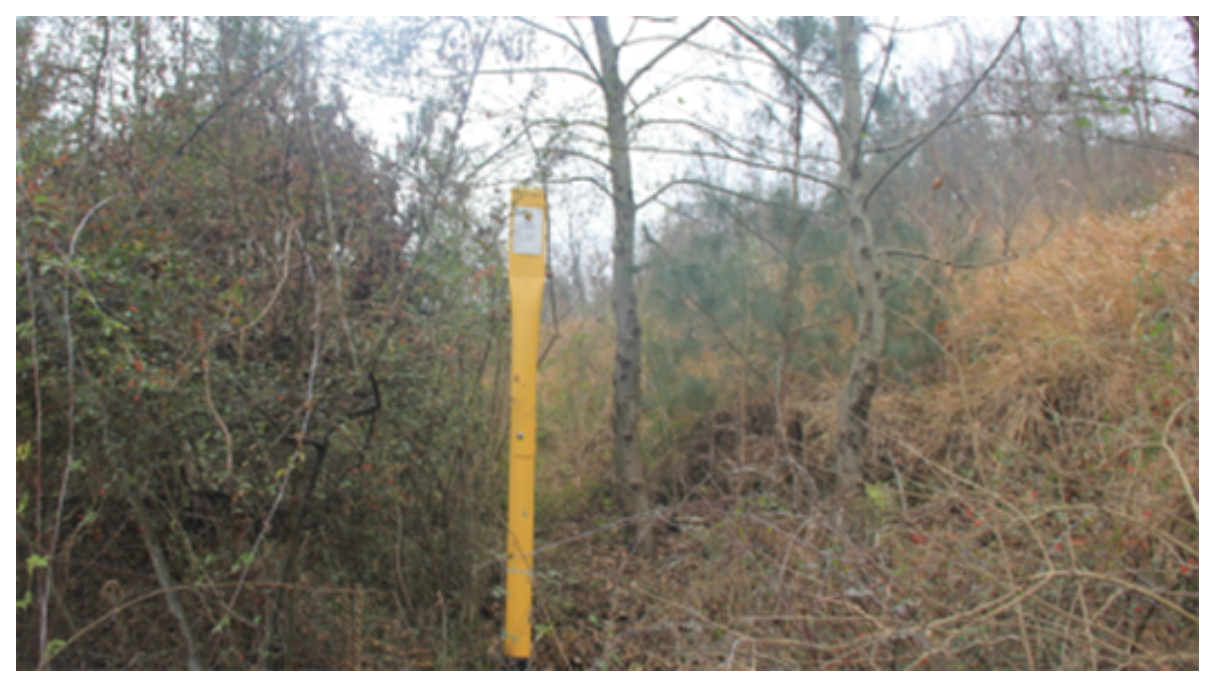

Figure H2. Vegetation environment of a pipeline section in the study area. 


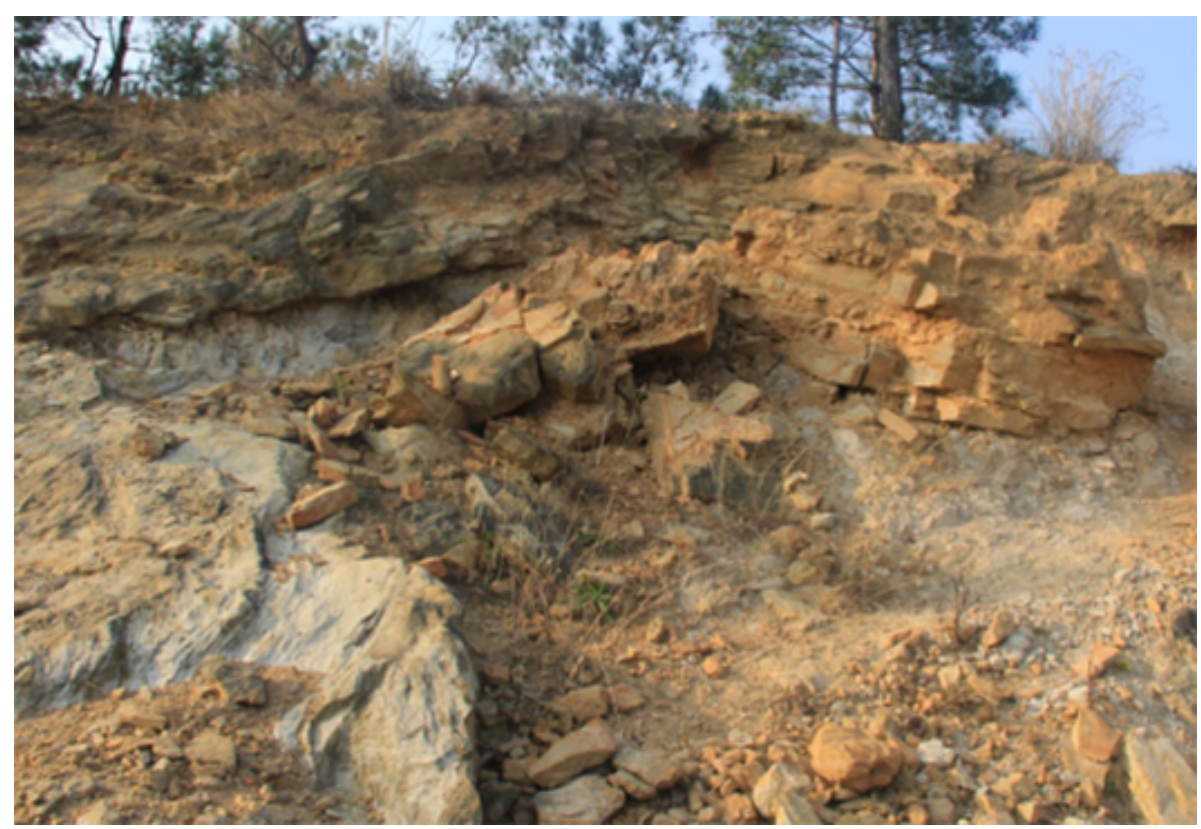

Figure H3. Outcropping of rock strata in the study area. 
Author contributions. JX conceived and designed the experiments, MS performed the experiments and analyzed the data, $\mathrm{HZ}$ wrote the paper and WC helped to prepare the paper. YY helped edit language and MS, YC and JW helped draw the maps. All authors read and approved the final paper.

Competing interests. The authors declare that they have no conflict of interest.

Special issue statement. This article is part of the special issue "Advances in computational modelling of natural hazards and geohazards".

Acknowledgements. The study has been funded by the Strategic Priority Research Program of Chinese Academy of Sciences (XDA20030302), IWHR (China Institute of Water Resources and Hydropower Research) National Mountain Flood Disaster Investigation Project (SHZH-IWHR-57), Scientific and Technological Innovation Team Project of Southwest Petroleum University (2017CXTD09) and the Open Topic of Digital Fujian Institute of Large Data for Natural Disaster Monitoring (NDMBD2018003).

Edited by: Albert J. Kettner

Reviewed by: two anonymous referees

\section{References}

Akgun, A., Kincal, C., and Pradhan, B.: Application of remote sensing data and GIS for landslide risk assessment as an environmental threat to Izmir city (west Turkey), Environ. Monit. Assess., 184, 5453-5470, https://doi.org/10.1007/s10661-0112352-8, 2012

Atta-Ur-Rahman and Shaw, R.: Hazard, Vulnerability and Risk: The Pakistan Context, Springer, Japan, 2015.

Avalon Cullen, C., Al-Suhili, R., and Khanbilvardi, R.: Guidance Index for Shallow Landslide Hazard Analysis, Remote. Sens., 8, 866, https://doi.org/10.3390/rs8100866, 2016.

Chang, H. and Kim, N. K.: The evaluation and the sensitivity analysis of GIS-based landslide susceptibility models, Geosci. J., 8, 415-423, https://doi.org/10.1007/BF02910477, 2004.

Ding, M. and Tian, S.: Landslide and Debris Flow Risk Assessment and Its Application, Science Press, Beijing, 2013.

Ding, M., Heiser, M., Hübl, J., and Fuchs, S.: Regional vulnerability assessment for debris flows in China - a CWS approach, Landslides, 13, 537-550, https://doi.org/10.1007/s10346-015-0578-1, 2016.

Dou, J., Yamagishi, H., Pourghasemi, H. R., Yunus, A. P., Xuan, S., Xu, Y., and Zhu, Z.: An integrated artificial neural network model for the landslide susceptibility assessment of Osado Island, Japan, Nat. Hazards, 78, 1749-1776, 2015.

Fall, M., Azzam, R., and Noubactep, C.: A multi-method approach to study the stability of natural slopes and landslide susceptibility mapping, Eng. Geol., 82, 241-263, 2006.

Feng, F., Wu, X., Niu, R., Xu, S., and Yu, X.: Landslide susceptibility assessment based on PSO-BP neural network, Science of Surveying Mapping, 42, 170-175, https://doi.org/10.16251/j.cnki.1009-2307.2017.10.027, 2017.

Feng, W., Zhang, T., and Zhang, Y.: Evaluating the stability of landslides in xianshizhai village and the pipeline vulnerability with their action, Journal of Geological Hazards \& Environment Preservation, 25, 83-88, 2014.

Gao, C. L., Li, S. C., Wang, J., Li, L. P., and Lin, P.: The Risk Assessment of Tunnels Based on Grey Correlation and Entropy Weight Method, Geotechnical \& Geological Engineering, 36, 1621, https://doi.org/10.1007/s10706-017-0415-5, 2017.

Guzzetti, F., Cardinali, M., and Reichenbach, P.: The Influence of Structural Setting and Lithology on Landslide Type and Pattern, Environ. Eng. Geosci., 2, 531-555, 1996.

Hao, J. and Liu, J.: Zonaion of Danger Degree of Geological Hazards over Lanzhou-Chengdu-Chongqing Products Pipeline, Oil \& Gas Storage \& Transportation, 49-53, 62, 68-69, 2008.

$\mathrm{He}, \mathrm{Y}$. and Fu, W.: Application of fuzzy support vector machine to landslide risk assessment, Journal of Natural Disasters, 18, 107 112, 2009.

Ho, K., Leroi, E., and Roberds, B.: Quantitative Risk Assessment: Application, Myths and Future Direction, ISRM International Symposium, Melbourne, 19 November 2000.

Hong, H., Pradhan, B., Xu, C., and Bui, D. T.: Spatial prediction of landslide hazard at the Yihuang area (China) using two-class kernel logistic regression, alternating decision tree and support vector machines, Catena, 133, 266-281, https://doi.org/10.1016/j.catena.2015.05.019, 2015.

Hsu, K. L., Gupta, H. V., and Sorooshian, S.: Artificial neural network modeling of the rainfall-runoff process, Water Resour. Res., 31, 2517-2530, https://doi.org/10.1029/95WR01955, 1995.

Hu, H., Dong, P., and Pan, J.: The Hail Risk Zoning in Beijing Integrated with the Result of Its Loss Assessment, Journal of Applied Meteorological Science, 22, 612-620, 2011.

Hu, W., Xu, Q., Wang, G. H., Asch, T. W. J. V., and Hicher, P. Y.: Sensitivity of the initiation of debris flow to initial soil moisture, Landslides, 12, 1139-1145, https://doi.org/10.1007/s10346-0140529-2, 2015.

Huo, F., Wang, W., Cao, Y., Wang, F., and Bureau, C. P.: China's Construction Technology of Oil and Gas Storage and Transportation and Its Future Development Direction, Oil Forum, 35, 44$51,2016$.

Inaudi, D. and Glisic, B.: Reliability and field testing of distributed strain and temperature sensors, P. Soc. Photo.-Opt. Ins., 6167, 2586-2597, https://doi.org/10.1117/12.661088, 2006.

Jaiswal, P., Westen, C. J. V., and Jetten, V.: Quantitative landslide hazard assessment along a transportation corridor in southern India, Eng. Geol., 116, 236-250, https://doi.org/10.1016/j.enggeo.2010.09.005, 2010.

Jia, Y., Zhao, J., Nan, Z., and Zhao, C.: The Application of Entropyright Method to the Study of Ecological Security Evaluation of Grassland - A Case Study at the Ecological Security Evaluation of Grassland to Pastoral Area of Gansu, Journal of Arid Land Resources Environmental \& Engineering Geoscience, 1, 17-21, https://doi.org/10.1016/S1872-5791(08)60002-0, 2007.

Jin, Y. and Meng, J. J.: Assessment and forecast of ecological vulnerability: A review, Chinese Journal of Ecology, 30, 2646-2652, 2011. 
Ke, F. and Li, Y.: The forecasting method of landslides based on improved BP neural network, Geotechnical Investigation \& Surveying, 42, 55-60, 2014.

Li, B. S. and Gao, Y. J.: Application of the improved fuzzy analytic hierarchy process for landslide hazard assessment based on RS and GIS, Paper presented at the International Conference on Intelligent Earth Observing and Applications, 9 December 2015, Guilin, https://doi.org/10.1117/12.2207381, 2015.

Li, G., Zhang, P., Li, Z., Ke, Z., and Wu, G.: Safety length simulation of natural gas pipeline subjected to transverse landslide, Electronic Journal of Geotechnical Engineering, 2016 (21.12), 4387-4399, http://www.ejge.com/2016/Ppr2016. 0375ma.pdf (last access: May 2017), 2016.

Li, J.: Wenchuan Earthquake and Secondary Geological Hazard Assessment Based on RS/GIS Technology, Master, China University of Geosciences, Beijing, China, 2010.

Li, J., Feng, J., Wang, W., and Zhang, F.: Spatial and Temporal Changes in Solar Radiation of Northwest China Based LMBP Neural Network, Scientia Geographica Sinica, 36, 780-786, https://doi.org/10.13249/j.cnki.sgs.2016.05.017, 2016.

Li, P. L., Tian, W. P., and Li, J. C.: Analysis of landslide stability based on BP neural network, Journal of Guangxi University, 38, 905-911, https://doi.org/10.19406/j.cnki.cqkjxyxbzkb.2011.01.029, 2011.

Li, S.: The Risk Assessment Study on the Environmental Geological Hazards along the West-East Nature Gas Pipeline, Master thesis, SouthWest JiaoTong University, Chengdu, China, 2008.

Li, S., Jian, J., Wu, Z., Li, S., Li, H., Bai, K., Ke, Q., Xu, Y., and Hu, Y.: A Design of the Geo-Environmental Management Database System for Guangyuan, City, Journal of Geological Hazards and Environment Preservation, 23, 36-42, 2012.

Liu, P. and Zhang, X.: Research on the supplier selection of a supply chain based on entropy weight and improved ELECTRE-III method, Int. J. Prod. Res., 49, 637-646, https://doi.org/10.1080/00207540903490171, 2011.

Liu, Y.: The characteristic and evaluation of collapse and landslide disaster along du-wen highway in Wenchuan earthquake region, Master, Lanzhou University, Lanzhou, 2009.

Liu, Y., Shi, Y., Lu, Q., Xiao, H., and Wu, S.: Risk Assessment of Geological Disasters in Single Pipe Based on Scoring Index Method: A Case Study of Soil Landslide, Natural Gas Technology \& Economy, 9, 57-61, 79, 2015.

Luo, Z. F. and Tan, D. J.: Landslide Hazard Evaluation in Debris Flow Catchment Area Based on GIS and Information Method, China Safety Science Journal, 21, 144-150, https://doi.org/10.1631/jzus.B1000265, 2011.

Mansour, M. F., Morgenstern, N. R., and Martin, C. D.: Expected damage from displacement of slow-moving slides, Landslides, 8, 117-131, https://doi.org/10.1007/s10346-010-0227-7, 2011.

Pal, R.: Entropy Production in Pipeline Flow of Dispersions of Water in Oil, Entropy, 16, 4648-4661, https://doi.org/10.3390/e16084648, 2014.

Peng, L., Deng, W., Zhang, H., Sun, J., and Xiong, J.: Focus on economy or ecology? A three?dimensional trade-off based on ecological carrying capacity in southwest China, Nat. Resour. Model., e12201, 2018.

Qiu, D., Niu, R., Zhao, Y., and Wu, X.: Risk Zoning of EarthquakeInduced Landslides Based on Slope Units: A Case Study on
Lushan Earthquake, Journal of Jilin University, 45, 1470-1478, https://doi.org/10.13278/j.cnki.jjuese.201505201, 2015.

Rafiq, L. and Blaschke, T.: Disaster risk and vulnerability in Pakistan at a district level, Geomat. Nat. Haz. Risk., 3, 324-341, https://doi.org/10.1080/19475705.2011.626083, 2012.

Ray, P. K. C., Dimri, S., Lakhera, R. C., and Sati, S.: Fuzzy-based method for landslide hazard assessment in active seismic zone of Himalaya, Landslides, 4, 101-111, https://doi.org/10.1007/s10346-006-0068-6, 2007.

Sari, D. A. P., Innaqa, S., and Safrilah: Hazard, Vulnerability and Capacity Mapping for Landslides Risk Analysis using Geographic Information System (GIS), IOP Conference Series: Materials Science and Engineering, 209, 012106, https://doi.org/10.1088/1757-899X/209/1/012106, 2017.

Sarkar, S. and Gupta, P. K.: Techniques for Landslide Hazard Zonation - Application to Srinagar-Rudraprayag Area of Gar, J. Geol. Soc. India, 65, 217-230, 2005.

Shi, S.: Risk Analysis for Pipeline Construction about Third Party Damage Based on Triangular Fuzzy Number and Fault Tree Theory, Journal of Chongqing University of Science \& Technology, 13, 91-94, https://doi.org/10.19406/j.cnki.cqkjxyxbzkb.2011.01.029, 2011.

Su, G. and Deng, F.: On the Improving Backpropagation Algorithms of the Neural Networks Based on MATLAB Language: A Review, Bulletin of Science \& Technology, 2, 130-135, https://doi.org/10.13774/j.cnki.kjtb.2003.02.012, 2003.

Wang, P., Xu, Z., Bai, M., Du, Y., Mu, S., Wang, D., and Yang, Y.: Landslide Risk Assessment Expert System Along the Oil and Gas Pipeline Routes, Adv. Mat. Res., 418-420, 1553-1559, https://doi.org/10.4028/www.scientific.net/AMR.418-420.1553, 2012.

Wang, Y., Hao, J., Zhao, F., and Fang, L.: A Discussion on Regional Risk Zoning of Geological Hazard in the Worst-hit Area of the Wenchuan Earthquake in Shaanxi Province, Journal of Catastrophology, 26, 35-39, https://doi.org/10.1007/s12583011-0163-z, 2011.

Wu, Z. and Wang, H.: Super-resolution Reconstruction of SAR Image based on Non-Local Means Denoising Combined with BP Neural Network, 2016.

Wu, T. H., Tang, W. H., and Einstein, H. H.: Landslides: investigation and mitigation, chapter 6 - landslide hazard and risk assessment, Transportation Research Board, 106-118, 1996.

Xiang, L. Z., Cui, P., Zhang, J. Q., Huang, D. C., Fang, H., and Zhou, X. J.: Triggering factors susceptibility of earthquakeinduced collapses and landslides in Wenchuan County, Journal of Sichuan University, 42, 105-112, 2010.

Xin, Y., Chong, X. U., and Dai, F. C.: Contribution of strata lithology and slope gradient to landslides triggered by Wenchuan Ms 8 earthquake, Sichuan, China, Geological Bulletin of China, 28, 1156-1162, 2009.

Xiong, H., Ran, Y., Xiong, G., Li, S., and Ye, L.: Study on deformation prediction of landslide based on genetic algorithm and improved BP neural network, Kybernetes, 39, 1245-1254, 2010.

Ye, C., Jiang, H., Yao, A., Xia, Q., and Zhao, X.: Study on risk controlling method of third party construction damage on oil and gas pipeline, Journal of Safety Science \& Technology, 9, 140145, 2013. 
Yun, L. and Kang, L.: Reliability Analysis of High Pressure Buried Pipeline under Landslide, Appl. Mech. Mater., 501-504, 10811086, https://doi.org/10.4028/www.scientific.net/AMM.501504.1081, 2014.

Zhang, Q., Xu, Q., Wu, L., and Li, J.: BP neural network model for forecasting volume of landslide group in Nanjiang, Hydrogeology and Engineering Geology, 42, 134139, https://doi.org/10.16030/j.cnki.issn.1000-3665.2015.01.23, 2015
Zhang, Y., Shi, J., Gan, J., and Liu, C.: Analysis of Distribution Characteristics and Influencing Factors of Secondary Geohazards in Guangyuan City - Taking Chaotian District as an Example, Journal of Catastrophology, 26, 75-79, https://doi.org/10.1007/s12182-011-0118-0, 2011.

Zheng, J. Y., Zhang, B. J., Liu, P. F., and Wu, L. L.: Failure analysis and safety evaluation of buried pipeline due to deflection of landslide process, Eng. Fail. Anal., 25, 156-168, https://doi.org/10.1016/j.engfailanal.2012.05.011, 2012. 